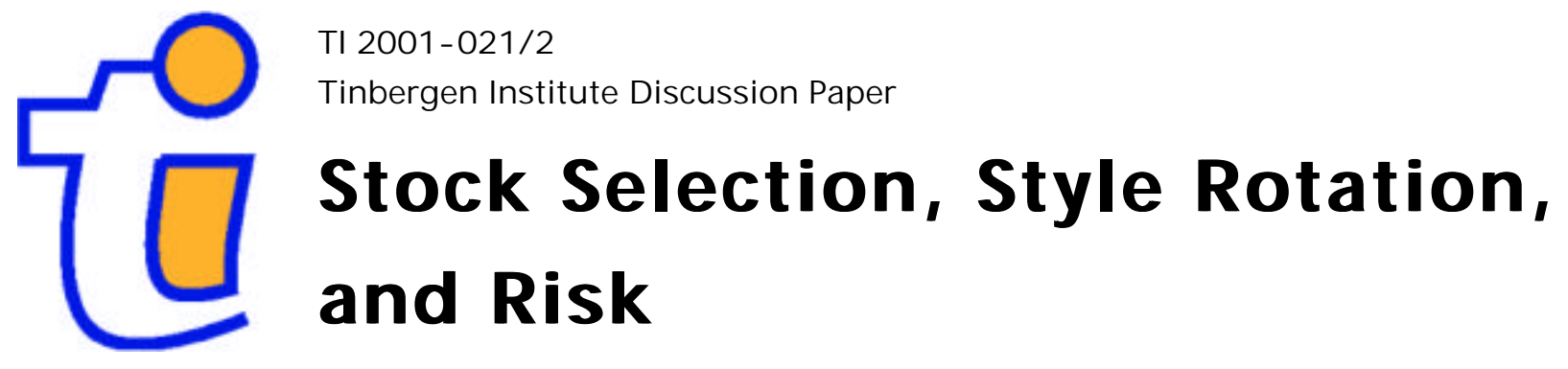

\author{
André Lucas \\ Ronald van Dijk \\ Teun Kloek
}




\section{Tinbergen Institute}

The Tinbergen Institute is the institute for economic research of the Erasmus Universiteit Rotterdam, Universiteit van Amsterdam and Vrije Universiteit Amsterdam.

\section{Tinbergen Institute Amsterdam}

Keizersgracht 482

1017 EG Amsterdam

The Netherlands

Tel.: $\quad+31 .(0) 20.5513500$

Fax: $\quad+31 .(0) 20.5513555$

\section{Tinbergen Institute Rotterdam}

Burg. Oudlaan 50

3062 PA Rotterdam

The Netherlands

Tel.: $\quad+31 .(0) 10.4088900$

Fax: $\quad+31 .(0) 10.4089031$

Most recent TI discussion papers can be downloaded at http:// www.tinbergen.nl 


\title{
Stock Selection, Style Rotation, and Risk*
}

\author{
André Lucas ${ }^{\dagger \dagger}$
}

\author{
Ronald van Dijk \ $^{\S}$
}

\author{
Teun Kloek $\| \S$
}

This version: February 12, 2001

\begin{abstract}
Using US data from June 1984 to July 1999, we show that the impact of firm-specific characteristics like size and book-to-price on future excess stock returns varies considerably over time. The impact can be either positive or negative at different times. This time variation is partially predictable. We investigate whether the partial predictability signals security mispricing or risk compensation by formulating alternative modeling strategies. The strategies are compared empirically. In particular, we allow for a state-dependent choice of investment styles rather than a once-and-for-all choice for a particular style, for example based on high book-to-price ratios or small market cap values. Using alternative ways to correct for risk, we find significant and robust excess returns to style rotating investment strategies. Business cycle oriented approaches exhibit the best overall performance. Purely statistical models for style rotation or fixed investment styles reveal less robust behavior.
\end{abstract}

Key words: investment style; time-varying parameters; risk compensation; business cycles.

${ }^{*}$ We thank Christopher Gilbert, Stacey Nutt, Herbert Rijken, an associate editor and anonymous referee, and seminar participants at the IBES conference Amsterdam, Free University Amsterdam, and the University of Ghent for useful comments and suggestions. The return and firm data were generously provided by VESTEK Systems Inc. André Lucas also thanks the Dutch Organization for Scientific Research (N.W.O.) for financial support. Correspondence to: alucas@econ.vu.nl, ronald.van.iim.dijk@mail.ing.nl, or kloek@few.eur.nl.

${ }^{\dagger}$ Dept. Finance and Financial Sector Management, Vrije Universiteit, De Boelelaan 1105, NL-1081HV Amsterdam, the Netherlands.

$\ddagger$ Tinbergen Institute Amsterdam, Keizersgracht 482, NL-1017EG Amsterdam, the Netherlands.

§ING Investment Management, Dept. Quantitative Research, the Netherlands.

`Dept. Finance, Faculty of Economics, Tilburg University, Postbus 90153, 5000 LE Tilburg, the Netherlands.

"Dept. Econometrics and Econometric Institute, Erasmus University Rotterdam, P.O. Box 1738, NL-3000DR Rotterdam, the Netherlands. 


\section{Introduction}

In examining the forecasting power of firm characteristics for excess returns, the academic literature conventionally focusses on long-term averages of monthly and annual returns. The systematic patterns found provide evidence that some equity classes generate above-average returns in the long run. In particular, value stocks outperformed growth stocks historically, and small capitalization stocks had higher annual returns than large capitalization stocks. See for example the papers of Fama and French (1992), La Porta (1996), Daniel and Titman (1997), Barber and Lyon (1997) and Lewellen (1999). In the investment management industry nowadays value and size strategies are used for discriminating relative future performance. This implementation is known as style investing.

At least three alternative theories have been put forward to explain the long-term outperformance of value and small capitalization stocks. First, the firm variables might proxy for a risk factor. Fama and French (1993), Jensen, Johnson and Mercer (1997) and Lewellen (1999) argue that the higher returns are a compensation for higher risk. Firms with similar firm characteristics are sensitive to the same macroeconomic factors like growth surprises and interest rate risk. A second and alternative view is that the firm variables provide information about secturity mispricing. Lakonishok, Shleifer and Vishny (1994) suggest that the higher returns are due to an incorrect extrapolation of past stock performance. La Porta (1996) finds evidence that value strategies work because expectations about future growth in earnings are too optimistic. As a third possible reason for reported outperformance, it can be argued that unexpected technological innovations are historically more related to particular equity classes. As a result, the uncovered return patterns can be due to data snooping, see, e.g., Lo and MacKinlay (1990), Black (1993) and MacKinlay (1995).

The performance of value or size related investment styles is not stable over time. Some periods depart from the long-term patterns documented in the literature. Chan, Karceski and Lakonishok (1999), for example, show that the regular size and value effects are inverse over the period 1990 through 1998. This can be a major worry for professional investment managers with value or size-based investment styles. Returns over a multi-year period are frequently not a sufficient factor to consider a particular fixed investment style a success. Professional money managers are often judged by the intrayear returns relative to a prespecified benchmark. Both annual outperformance and intra-year variability of the outperformance are important (Roll, 1992). Managers are therefore looking for systematic patterns in the timevarying impact of value and size on returns in order to enhance their per- 
formance. As argued above, such patterns can be caused by macroeconomic conditions.

Some authors use the time-variation in the relation between firm characteristics and returns to investigate whether the mispricing or risk compensation view provides a more plausible explanation for realized excess returns. Fama and French (1993), Daniel and Titman (1997), and Lewellen (1999), for example, examine the returns on value and size based investment styles using a factor model with 3 factors: (i) the returns on a value-weighted market portfolio, (ii) the excess returns on a small-capitalization over a largecapitalization portfolio, and (iii) the excess return on a high book-to-market portfolio over a low book-to-market portfolio. By relating returns on value or size-based investment styles to current realizations of the risk factors, the authors argue that excess returns are more in line with the risk compensation rather than with the mispricing view.

Our paper adds to the current literature on asset pricing by examining further whether a multifactor model that includes Size and book-to-price ratios, explains returns. A positive finding would support the risk explanation for the predictive power of value and size indicators. Previous papers focused on multifactor models that lead to fixed investment styles, mainly small Size and high book-to-price. By contrast, our model allows the investment style to vary over time. We investigate whether style effectiveness shows any persistence over time. In particular, we test whether the impact of Size and book-to-price varies with macroeconomic conditions. For this, we formulate both statistical time-series models for style rotation and macroeconomic regression models. If excess returns of a particular style rotation scheme are sufficiently explained by the product of risk factors and factor loadings, then the risk compensation view seems to be valid.

As a first result, we find that for pure statistical rotation schemes the risk compensation view provides an adequate explanation of realized excess returns. More striking results are obtained, however, if we consider a variant of our model in which we relate style effectiveness explicitly to macroeconomic conditions. This model produces a bilinear forecasting framework. Bilinear models to examine the value and size style can also be found in $\mathrm{He}$, Kan, $\mathrm{Ng}$ and Zhang (1996). Our approach and goals, however, differ markedly. They use 25 portfolios sorted by book to market and size and they assume that expectations of investors are unbiased. Their aim is to find a disrete time equilibrium multifactor model that is consistent with the returns of the 25 portfolios. He et al. (1996) conclude that their models are inconsistent with the portfolio return data. By contrast, we aim at predicting future individual stock returns. No assumptions about rational expectations are made.

We use two macroeconomic variables in our style rotation model. The first 
variable is the term-spread of interest rates, which is defined as the long-term interest rate minus the short-term rate. At least two reasons can be given for the potential influence of this variable on expected stock returns. First, the term spread can be considered as an indicator of economic activity. In an expanding economy it decreases because short rates generally rise more than long rates. Similarly, during a contraction it generally increases. Hence, the term spread may affect expected stock market returns because of the effect on expected company earnings (see, also, Schwert (1990), Chen (1990) and Jensen, Johnson and Mercer (1996)). This suggests that in periods of a small term spread some equity classes, likely to be small and rapidly growing firms, show higher returns as a results from higher and better quality earnings expectations. Second, the term spread affects the sensitivity of stock prices to changes in interest rates. An increase in the term spread causes short-term earnings to play a relatively more important role in a dividend or free-cash flow discount model, while the long-run earnings are relatively less significant. How shifts of the term structure of interest rates influence a stock price depends on the distribution of earnings and, likely, on the equity class. Consequently, interest rate risks and equity premiums may differ over the equity classes. The second macroeconomic variable is a composite of leading indicators of the business cycle. Different equity classes may profit in different ways from changes in the business cycle. We hypothesize that especially small and growing firms are likely to be flexible to react on and profit from the changing economic environment.

The results reveal that style rotation based on macroeconomic predictive variables generates historical excess returns. In order to prevent data snooping biases, we check the robustness of our results to a range of alternative specifications. In particular, we show that the excess returns remain significant after various ways of risk-correction. In addition to the earlier literature, we also investigate the robustness of the results with respect to the portfolio rebalancing period. We use monthly, quarterly, semi-annual, and annual horizons. It turns out that risk corrected returns reveal a remarkable stability for the business cycle based model, especially for the stocks with the strongest ex-ante predicted outperformance. By contrast, excess returns on traditional, fixed investment styles (size or book-to-price) or on purely statistical style rotation schemes are not robust with respect to the rebalancing horizon. Moreover, the business cycle model returns are also robust to the way portfolios are constructed and the way potential outliers are dealt with. In short, the results point out that the rotating investment styles based on firm characteristics and macroeconomic predictors provide consistent and robust (risk-corrected) excess returns. These returns appear incompatible with the standard risk compensation view. As such, they provide a further 
dimension to the current debate by allowing more flexibility in the choice of investment strategies.

The paper is organized as follows. In Section 2 we give a description of the data. In Section 3 we describe the time-varying impact of firm characteristics on excess returns. We focus on value and size-based investment styles and test whether there is any evidence of systematic patterns in the time-variation. In Section 4 we provide alternative modeling approaches to transform predictability into style rotation schemes. In Section 5 we implement the models and discuss the results. Section 6 concludes the paper and gives directions for future research.

\section{The Data}

The firm-specific data come from two sources. Monthly stock price and dividend data in the period from June 1984 to July 1999 come from Interactive Data Corporation (IDC). IDC is a leading provider of securities pricing data. Our prices and dividends are adjusted for stock splits. Monthly total returns are calculated using these price and dividend data. The monthly returns are used to compute quarterly, semi-annual, and annual returns. For the annual frequency we will consider the July-July end of month returns. For the quarterly and semi-annual frequencies, the annual return period is divided into an appropriate number of subperiods. Hence, non-overlapping samples are used. The COMPUSTAT database provides book values, which are used to compute the Book-to-Price (BP) ratio. Size is measured as the logarithm of market capitalization. The book-to-price and size variable are cross-sectionally demeaned to remove any trends.

The stock universe is the Russell 3000, meaning that we observe 7860 stocks in total over the sample period. Most of these, however, are observed for only part of the complete sample period (including dead stocks). The Russell 3000 universe comprises the 3000 largest US companies based on total market capitalization. They represent approximately 98 per cent of the investable US equity market.

We use two sources for our macroeconomic variables. First, we use a seasonally adjusted composite index of leading indicators made public by the Business Cycle Indicators section of The Conference Board. The index is constructed by a (weighted) averaging of ten individual series that are supposed to have turning points that occur before those in aggregated economic activity. Among these indices are (i) average working hours by production workers, (ii) initial claims for unemployment insurance, (iii) new orders for consumer goods, (iv) new orders for capital goods, (v) vendor performance, 
(vi) residential building permits, (vii) S\&P 500 price movements, (viii) money supply M2, (ix) interest rate spread, and (x) index of consumer expectations. The leading indicator is transformed into annual growth rates. Second, the Federal Reserve provides information on spreads in the term structure of interest rates. This type of variable is also a component of the Business Cycle indicator, in which it is the difference between the 10-years Treasury bond rate and an overnight interbank borrowing rate. Our definition of the term-spread variable depends on the data frequency in the modeling and backtesting frameworks. For the monthly return frequency, we consider the difference between the yield on ten year treasury notes (constant maturity) and one month certificates of deposit (CDs). For the quarterly, semi-annual, and annual return frequencies, we replace the yield on the one month CDs by the yield on three month, six month, and one year treasury bills, respectively.

\section{Time Variation}

In this section we illustrate how the effect of Size and B/P varies over time. As a reference point, we use the standard factor model representation of returns,

$$
R_{i t}=\beta_{i t}^{\prime} f_{t}+\varepsilon_{i t},
$$

where $R_{i t}$ is the (excess) return on asset $i$ over period $t, \beta_{i t}$ is a $k$-dimensional vector of factor loadings, $f_{t}$ is a vector of common risk factors, and $\varepsilon_{i t}$ is an idiosyncratic risk component independent of $f_{t}$. Of course, (1) is too general to be useful. One way to go about is to drop the time index from $\beta_{i t}$ and use observables for $f_{t}$, see for example Fama and French (1993). Another way is to proxy the $\beta_{i t}$ by observable firm characteristics, like size or book-to-price, see Lewellen (1999). Taking a linear specification $\beta_{i t}=\Gamma^{\prime} x_{i, t-1}$, we obtain

$$
R_{i t}=x_{i, t-1}^{\prime} \Gamma f_{t}+\varepsilon_{i t},
$$

with $x_{i, t-1}$ an $m$-dimensional vector of firm characteristics containing for example size and book-to-price of firm $i$ at time $t-1$, and $\Gamma$ an $(m \times k)$ parameter matrix. Note that $x_{i, t-1}$ is lagged with respect to the return $R_{i t}$, such that it is known at the time of forecasting next period's return, see also Section 2. By defining $\gamma_{t}=\Gamma f_{t}$, we have a regression model with time-varying coefficients,

$$
R_{i t}=x_{i, t-1}^{\prime} \gamma_{t}+\varepsilon_{i t},
$$

where the $\gamma_{t} \mathrm{~s}$ can be estimated using the cross-sectional dimension of the sample. Equation (3) clearly shows that $x_{i, t-1}$ has a time-varying impact on 
the return $R_{i t}$ and that this time variation is caused by the time-variation in the common risk factors $f_{t}$. As both $x_{i, t-1}$ and $f_{t}$ may contain a constant term, (2) specializes to the model of Lewellen (1999) if $x_{i, t-1}$ is the (portfolio) book-to-price ratio and $f_{t}$ contains the 3 factors of Fama-French: market return, return differential between a large and small cap portfolio, and return differential between a high and low book-to-price portfolio. Lewellen uses this model to support his claim that the book-to-price ratio is mainly an indicator for risk and not as much of (anomalous) excess return.

In the present paper we take a different perspective. Given (3), we investigate whether there is any persistence in the sign and/or magnitude of $\gamma_{t}$ over time. If this is the case, it would allow for a timely switch from for example a large cap to a small cap strategy, or from a value to a growth strategy. Persistence in $\gamma_{t}$ can be caused by for example persistence in the underlying common factors $f_{t}$. Alternatively, there might be a omitted variables bias resulting in some persistence in $\hat{\gamma}_{t}$. This can be tested in two ways. First, one can postulate observables for $f_{t}$ and test whether these are serially uncorrelated. This, however, would render one prone to misspecification of the risk factors. Therefore, we follow a second route and estimate (3) per cross-section. In this way, we obtain a time series of coefficients for the constant term, the size variable, and the book-to-price ratio. These time series are plotted in Figures 1 and 2 for the period June 1984 up to July 1999.

Figures 1 and 2 show that for both Size and B/P there is a large number of times the effect on returns is positive, while for a similar number of times the effect is negative. This result does not change if we only take the significant coefficients into account (not shown). The results imply that there are periods during which Size has a positive effect on returns. During other periods, however, the effect might be either opposite or statistically insignificant. Such time variation has important implications for practical asset management. At different points in time either a large or small cap investment style may be preferable. Styles that are very effective now can easily become obsolete or even counterproductive after a relatively short period. Also when we look at the scatter-diagrams of the coefficients in Figure 2, we see that there were many periods during which either a large or small cap strategy combined with either a value or growth strategy proved most profitable. So also the optimal combination of different styles varies over time. All these results are qualitatively similar and stable over the different sampling frequencies.

The time variation in the impact of size and book-to-price on excess returns might signal that these variables correlate with risk factors. On the other hand, it might be the case that changes in the direction of the effect are partially predictable. Given the time variation in the regression coefficients, we perform a preliminary data analysis on the coefficients to see whether 

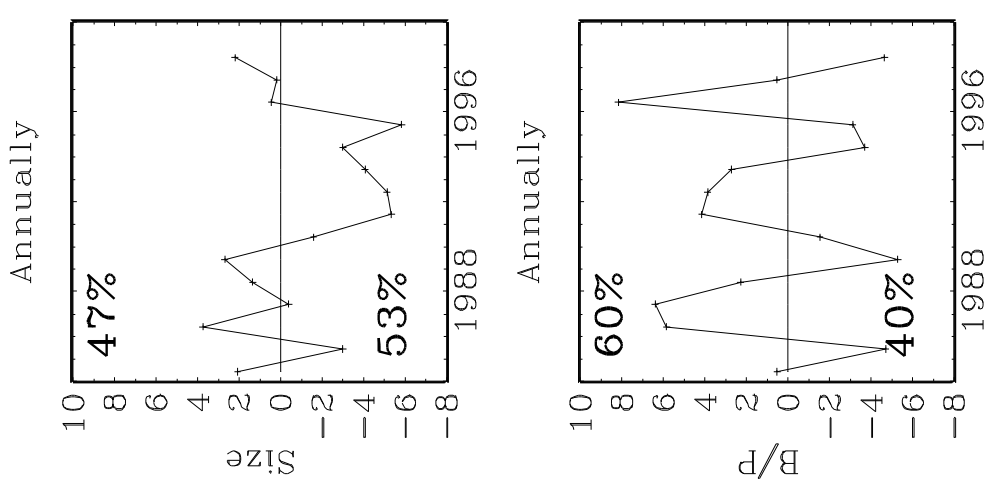




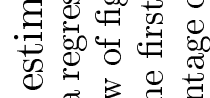
궁 శ్తి ఏ్二

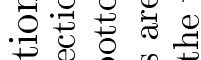

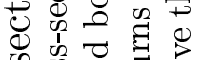
क क की ర்َ .. 㐘导 ๑.

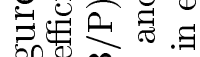

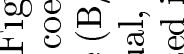

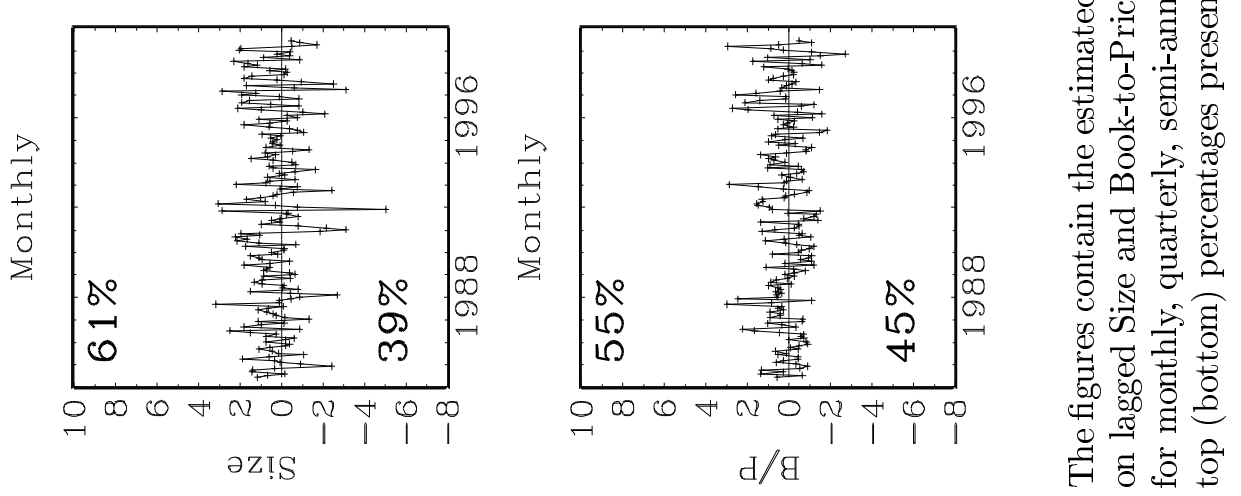



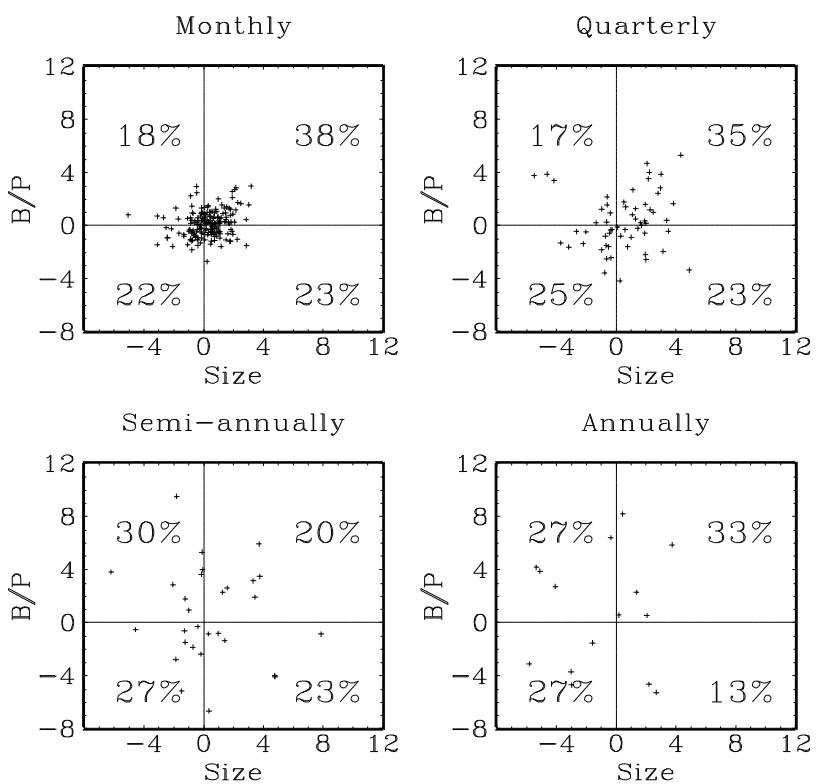

Figure 2: Scatter diagrams of cross-sectionally estimated coefficients The figures contains scatter diagrams of the estimated coefficients per cross-section of a regression of future excess returns in excess of an equally weighted portfolio on Size and Book-to-Price (B/P). The percentages give the fraction of coefficient couples (Size,B/P) present in the quadrant.

there are any signs of serial correlation. If present, the amount of serial correlation signals to what extent we can expect to capture part of the timevariation in a predictive framework. The results are given in Table 1 for the 4 different investment horizons discussed earlier.

At the monthly frequency, the Size coefficient shows significant (at the $10 \%$ level) positive autocorrelation using the first partial autocorrelation (AR1). The Cowles-Jones (CJ) test is not significant, but exceeds unity. The mean coefficient is insignificantly positive, while the median is significantly positive at the $1 \%$ level. This suggests that large cap stocks have outperformed small ones on a monthly basis over the past 15 years, see also Chan et al. (1999). The coefficient of B/P is insignificant on average (as well as in the median sense) at the monthly frequency and shows no serial autocorrelation. At the quarterly frequency, the positive autocorrelation in Size has reversed to an insignificant negative correlation. The CJ-test points in the same direction. For the $\mathrm{B} / \mathrm{P}$ ratio, an insignificant negative correlation is found. At semi-annual and annual frequencies, no significant correlations are found. This might be due to the limited number of observations at that frequency. The partial autocorrelation and the CJ test generally point in the same direction, except for the $\mathrm{B} / \mathrm{P}$ ratio at the semi-annual frequency. Also 
Table 1: Summary statistics for cross-sectional coefficients

\begin{tabular}{lrrrrrr}
\hline \hline & $\%>0$ & Mean & Std & Median & AR1 & CJ \\
\hline \multirow{7}{*}{ Size } & 57.5 & 0.16 & 1.32 & $0.20^{a}$ & $0.13^{c}$ & 1.17 \\
B/P & 53.0 & 0.10 & 0.84 & 0.05 & -0.00 & 0.98 \\
& \multicolumn{7}{c}{ Quarterly horizon } \\
Size & 56.7 & 0.16 & 2.74 & $0.58^{a}$ & -0.25 & 0.90 \\
B/P & 51.7 & 0.42 & 2.14 & 0.08 & 0.10 & 1.11 \\
& \multicolumn{7}{c}{ Semi-annual horizon } \\
Size & 43.3 & -0.29 & 3.99 & $-0.51^{a}$ & -0.45 & 0.71 \\
B/P & 50.0 & 1.59 & 7.94 & $-0.15^{a}$ & -0.10 & 1.42 \\
& \multicolumn{7}{c}{ Annual horizon } \\
Size & 33.3 & $-1.69^{c}$ & 3.52 & $-0.67^{a}$ & 0.41 & 1.33 \\
B/P & 46.7 & 1.17 & 6.90 & $-0.40^{a}$ & 0.18 & 1.00 \\
\hline
\end{tabular}

This table contains summary statistics of cross-sectional regressions of returns on Size and B/P, see (1). The results are presented for 4 data frequencies. The first column gives the percentage of positive coeffients $(\%>0)$. The columns labeled Mean, Std, and Median give the time series average, the standard deviation, and median of the estimated coefficients, respectively. The column labeled AR1 gives the first order autocorrelation. The column labeled CJ is the Cowles-Jones (1937) test statistic based on the signs of the coefficients. Under the null of no sign predictability, the statistic should be equal to 1 . Significance of the statistics in this table at the 1,5 , and 10 percent level is indicated by ${ }^{a},{ }^{b}$, and ${ }^{c}$, respectively. 
the mean and median of $\mathrm{B} / \mathrm{P}$ at the two longest frequencies reveal conflicting results. Looking at the graphs in Figure 1, it is not surprising to see a difference between the outlier non-robust (Mean,AR1) and outlier robust (Median,CJ) statistics in the table. The medians are significantly negative, while the means are insignificantly positive. This is due to the large value of the coefficient during 1992. In later sections, we also check the robustness of our results with respect to outliers. The results in Table 1 point out that there is only weak preliminary evidence on the predictability of Size and B/P impact. Monthly frequencies appear most promising. Given the strong variation in predictability for varying data frequencies, it is important to check the robustness of subsequent results with respect to the rebalancing period in order to prevent data snooping biases. This is done in Section 5.

\section{Modeling Frameworks}

Given the evidence from the previous section on potential serial correlations in the impact of Size and B/P on returns, we now discuss alternative modeling frameworks for capturing the time-variation in $\gamma_{t}$ in (3). We distinguish between two approaches. First, we consider simple statistical approaches like pooling, averaging cross-sectional coefficients, and building time-series models for the coefficients. Second, we consider a framework where time variation in the coefficients is related to economic business cycle variables.

\subsection{Pooling}

As a first approach to tackling the time variation, one can pool all available firms and time periods $1, \ldots, t$ and do a panel data analysis of (3). This produces an estimate of $\gamma_{t}$, which together with the firm characteristics $x_{i t}$ can be used to forecast future returns. The coefficient $\gamma_{t}$ is indexed by time, because it depends on the sample used (cross section 1 up to $t$ ). As more data become available, two approaches may be followed: the new observations may be added to the sample with or without deleting the oldest observations. If old observations are not deleted, the sample is extended. If old observations are deleted, one uses a rolling window to estimate $\gamma_{t}$.

The pooling approach is a valid procedure if the common risk factors $f_{t}$ are serially uncorrelated with constant conditional mean $f=E_{t-1}\left(f_{t}\right)$. In that case, we can rewrite (3) as

$$
R_{i t}=x_{i, t-1}^{\prime} \gamma+\tilde{e}_{i t},
$$


with $\gamma=\Gamma f$, and $\tilde{e}_{i t}=e_{i t}+x_{i, t-1}^{\prime} \Gamma\left(f_{t}-f\right)$. The error term in (4) is now heteroskedastic. Consequently, the OLS estimator for $\gamma$ is still valid, though not efficient. If $E\left(f_{t}\right)$ is non-constant and slowly evolves over time, (4) can still be a useful approximative model for forecasting.

An additional methodological issue concerns the elimination of redundant variables. Starting from a regression model including both Size and B/P, we sequentially eliminate the variables that have absolute $t$-values below 1 . In this way we hope to enhance the forecasting power of the model, as argued by Pesaran and Timmermann (1995).

\subsection{Averaging}

A similar approach to pooling is that of time-series averaging of cross-sectional coefficients. As in Section 3, we can estimate (3) per cross-section. Using the estimated values $\hat{\gamma}_{t}$ for each cross-section $1, \ldots, t$, the average effect at time $t$ can be computed as

$$
\bar{\gamma}_{t}=\sum_{s=1}^{t} \hat{\gamma}_{s} / t
$$

The value of $\bar{\gamma}_{t}$ can then be used to forecast $R_{i t}$. This approach is very similar to the pooling approach and, therefore, shares the same advantages and disadvantages.

\subsection{Random walk model}

The main disadvantage of both the averaging and the pooling approach is that the coefficients are relatively rigid over time. In case of swiftly switching coefficients $\gamma_{t}$, these approaches are less suited. In a rapidly changing environment it might be much more useful to base the current estimate of $\gamma_{t}$ to be used for forecasting on recent data only. As an extreme, we consider a random walk forecast, where $\gamma_{t}$ is estimated by $\gamma_{t-1}$. We then use the information in the most recent cross-section only. This is a sensible approach if the true factor model underlying asset returns is a standard random coefficients model,

$$
\begin{aligned}
R_{i t} & =x_{i, t-1}^{\prime} \gamma_{t}+e_{i t} \\
& =x_{i, t-1}^{\prime} \gamma_{t-1}+\left(e_{i t}+x_{i, t-1}^{\prime} \eta_{t}\right)
\end{aligned}
$$

where $\eta_{t}$ is an innovation to the random walk $\gamma_{t}=\gamma_{t-1}+\eta_{t}$. As demonstrated below in Subsection 4.4, using the cross-sectional estimate $\hat{\gamma}_{t}$ for $\gamma_{t+1}$ results in a consistent predictor. As the random walk model constitutes a good 
benchmark model in various fields of economics, we also incorporate it in our analysis. Clearly, (6) is the correct approach if the factors $f_{t}$ follow a random walk process.

\subsection{Autoregressive modeling}

Both the random walk and the averaging approach can be interpreted as using a weighted sum of past cross-sectional estimates to predict the future regression coefficients $\gamma_{t}$. Whereas the averaging approach distributes the weight evenly over all past cross-sections, the random walk methodology puts all weight on the most recent cross-section only. Alternatively, both methods can be viewed as special cases of the following scheme,

$$
\gamma_{t}=\mu+\Phi \gamma_{t-1}+\eta_{t}
$$

with $\Phi=0$ for the averaging method, and $\Phi=I$ and $\mu=0$ for the random walk approach. More generally, however, one can try to estimate $\mu$ and $\Phi$ unrestrictedly from the data. The principal difficulty with this is that we do not directly observe $\gamma_{t}$, but only the cross-sectional estimates $\hat{\gamma}_{t}$. Instead of directly incorporating (7) into (3) and doing full maximum likelihood estimation, we consider a simpler approach. First, we estimate the parameters in (7) by OLS using $\hat{\gamma}_{t}$ rather than $\gamma_{t}$. This gives us a biased estimate of $\mu$ and $\Phi$. Next, we introduce a bias correction in order to alleviate the potential bias in the estimate of $\Phi$. The bias correction is given in the Appendix. The parameters $\mu$ and $\Phi$ are estimated using cross-sections 1 up to $t$ in order to forecast $\gamma_{t+1}$.

\subsection{Business cycle indicators}

The approaches in the previous subsections are purely statistical. They do not try to relate the effectiveness of investment styles and the time-variation in $\gamma_{t}$ to economic conditions. Various studies have linked macroeconomic indicators to asset returns, e.g., Chen, Roll, and Ross (1986), Chen (1991), and Pesaran and Timmermann (1994,1995). The main idea underlying these

models is that differing growth prospects and expectations on discount factors can make stock investments more or less attractive at different points in time. Analogously, alternative investment styles can be preferred at different points in time. If, for example, one expects an increase in the level and slope of the term structure of interest rates, a switch from long duration to short duration stocks can be warranted. In terms of investment styles, this implies a switch from a growth strategy to a value strategy. Also, macroeconomic 
growth prospects and the associated uncertainty might affect different firms in different ways.

In order to capture these effects, we augment the set of regressors from $x_{i t}$ to $X_{i t}=x_{i t} \otimes M_{t}$, where $\otimes$ is the Kronecker product. For $M_{t}$, we use a set of business cycle predictors. In particular, $M_{t}$ contains a constant term, the term spread of interest rates $\left(\right.$ Term $\left._{t}\right)$ and the annual growth rate in the composite index of leading business cycle indicators $\left(\operatorname{Lead}_{t}\right)$. Both variables have potential predictive power to indicate stages of the business cycle. For the term structure of interest rates, see for example Pesaran and Timmermann $(1994,1995)$.

An alternative interpretation of the business cycle approach is that we predict the risk factors $f_{t}$ by a linear combination of $M_{t-1}$. If we let $\Gamma_{2}$ be a parameter matrix, we have

$$
\begin{aligned}
R_{i t} & =x_{i, t-1}^{\prime} \Gamma_{2} M_{t-1}+e_{i t} \\
& =\left(M_{t-1} \otimes x_{i, t-1}\right)^{\prime} \delta+e_{i t},
\end{aligned}
$$

where $\delta=\operatorname{vec}\left(\Gamma_{2}\right)$ contains the stacked columns of $\Gamma_{2}$. As with the pooling approach in Subsection 4.1, $\delta$ can be estimated using the cross-sections 1 up to $t$ to forecast cross-section $t+1$. Subsequently, we sequentially eliminate all regressors with absolute $t$-values below 1 to enhance the forecasting power of the model. In this way, we obtain an estimate $\hat{\delta}_{t+1}$ that together with $M_{t}$ and $x_{i, t}$ can be used in (9) to forecast $R_{i, t+1}$.

\section{Results}

In this section, we present the results of our empirical analysis. We first discuss the results of a monthly rebalancing period in depth. Next, we go over the results for longer holding periods. Finally, we discuss the robustness of the results.

\section{A. One-month returns}

Each month end, from June 1989 onwards, we obtain forecasts of stock returns using seven different approaches. All approaches use size and book to market as the factors for $x_{i t}$ in (3). The approaches differ in the way estimates of $\gamma_{t}$ are obtained, as discussed in Section 4. The use of different methods implies that different parts of the data set are used to estimate the parameters. The pooling, averaging, autoregressive, and business cycle methods employ data from June 1984 up to June 1989 to estimate the first set of parameters $\gamma_{t}$. After the end of June 1989, the panel extends through 
time and each month a new estimate for $\gamma_{t}$ is obtained. The random walk method uses previous month's data to estimate $\gamma_{t}$ each month.

We construct portfolio returns from the forecasts for individual stock returns as follows. First, we generate forecasts for the expected performance of each stock and select the stocks with a positive forecasted return. We thus concentrate on investment strategies where only long positions are allowed and absolute returns matter. Next, we sort the forecasted returns from high to low and construct five portfolios. Portfolio 1 contains the $20 \%$ highest predicted (positive) returns and Portfolio 5 the $20 \%$ smallest (positive) returns. The stocks are equally weighted in each portfolio. During the holding period of one month, the portfolios are not re-balanced. For a fixed Size style, we use present market capitalizations instead of predicted returns. Portfolio 1 contains the large caps, and Portfolio 5 the small caps. Similarly, for a fixed $\mathrm{BM}$ style we use the observed $\mathrm{B} / \mathrm{P}$ ratio, sorted from high to low. Panels $B$ through $H$ in Table 2 contain the investment results for the seven (possibly rotating) investment styles. Panel $A$ provides a benchmark for panels $B$ through $H$. It presents the investment results from the standard regression model

$$
R_{i t}=\lambda_{0 t}+\lambda_{1 t} \cdot \text { Size }_{i, t-1}+\lambda_{2 t} \cdot(B / P)_{i, t-1}+\varepsilon_{i t},
$$

where $\lambda_{0 t}, \lambda_{1 t}$ and $\lambda_{2 t}$ are parameters. In contrast to the other models, we estimate the parameters in (10) using cross-section $t$ only. This means that we assume that the returns of the next month, $r_{i t}$, are known. This provides the best linear predictor of future returns given the use of Size and $\mathrm{B} / \mathrm{P}$ as firm characteristics. As before, we use the predicted positive returns to construct five portfolios. The returns on these portfolios provide insight into the maximum performance that can be attained given the chosen set of predictors.

In this paper we focus on the economic properties of portfolios to assess which model or forecasting method performs best. Two criteria are used. First, we consider whether a forecasting method leads to portfolios that outperform a reference portfolio. We use an equally-weighted benchmark portfolio for this purpose. Rebalancing of the benchmark portfolio takes place at the moment as the new portfolios are constructed based on the forecasting models. A market-capitalization-weighted benchmark might be influenced by a persistent size bias. We check the robustness of our results with respect to the choice of benchmark later on. Second, we examine whether a monotonic relation exists between the returns of the Portfolios 1 through 5. Both criteria are examined before and after correcting for risk.

Panel $A$ shows that the average monthly return of Portfolio 1 equals 3.27, which is substantially higher than the return on the market portfolio. The 
latter equals 1.42, which only exceeds the return on Portfolio 5 in panel A. The results show that it can be economically interesting to attempt to forecast the time-variation in the relation between returns, Size and $B / P$. We now turn to the risk characteristics, which are given in the remaining rows of Panel A. The high return of Portfolio 1 is counterbalanced by a high standard deviation and tracking error, where the tracking error is defined as the time-series standard deviation of the difference between the portfolio's return and the benchmark. The standard deviations and tracking errors for Portfolios 2 through 5 are almost equal, implying that these portfolios can be mainly distinguished on the basis of excess returns. Standard deviations and tracking errors are symmetric risk measures. As investors are also interested in asymmetric risk, we also consider three alternative downside risk measures. The $k$ th order lower partial moments presented in the table are defined as the average of $\left|R_{t}^{M}-R_{i t}\right|^{k} \cdot 1\left\{R_{i t}<R_{t}^{M}\right\}$ over the forecast period. Here, $1\left\{R_{i t}<\right.$ $\left.R_{t}^{M}\right\}$ takes the value 1 if the portfolio return $R_{i t}$ falls below the market return $R_{t}^{M}$. Otherwise, it equals zero. For $k=0$, we obtain an estimate of the probability of shortfall with respect to the market benchmark return. This risk measure is closely related to Value-at-Risk, see Jorion (1996). For $k=1$ we obtain expected shortfall with respect to the benchmark, and for $k=2$ we obtain a semi-tracking error. Using these downside-risk measures, we see that the higher average returns on the perfect foresight portfolios are not offset by higher risk values. All risk measures appear monotonically increasing if we shift into stocks with smaller predicted positive returns. The turnover indicator for Portfolio 1 equals 32.4, which reveals that on average about 67.6 percent of the stocks are sold at portfolio construction. Perfect forsight thus results in an active trading strategy.

Panel $B$ shows that investing in stocks with particular $\mathrm{B} / \mathrm{P}$ ratios did not work in our sample period: the average returns of the five portfolios are below that of the market index (1.42). Our findings are consistent with the findings of Chan, Karceski and Lakonishok (1999). Panel $C$ shows a similar pattern: an investment style based on Size only did not generate excess returns with respect to passive index tracking. Panels $D$ through $G$ provide evidence that it is difficult to outperform the equally-weighted index using simple statistical approaches for style rotation. Except for Portfolio 1 of the autoregressive approach (1.47) and possibly the Random Walk approach (1.42), none of the returns lie above the benchmark return of 1.42. This corroborates the results in Table 1 that it is difficult to predict the future impact of Size and $\mathrm{B} / \mathrm{P}$ based on past regression coefficients only. In general, these findings support the efficient market hypothesis. Given the criteria formulated earlier, the Business Cycle method in Panel $H$ gives better results. The return on the top $20 \%$ of predicted positive returns (Portfolio 1) clearly exceeds 
the return on the market index. Also the next 20\% of stocks (Portfolio 2) still generate a positive return with respect to the benchmark of 1.42. Moreover, the returns are monotonically decreasing from Portfolio 1 through 5: weaker ex-ante predicted winners also show a weaker ex-post performance. The return of Portfolio 1 vis-à-vis Portfolio 5 for Panel $\mathrm{H}$ is not offset by a corresponding increase in risk. The weaker predicted winners clearly show both more symmetric and more downside-risk.

To test whether the forecasting power of Size and $B / P$ as shown in Panel $A$ of Table 2 generates significant risk-corrected excess returns, we use the following test. We perform a time-series regression of the portfolio returns on a constant and the return of an equally-weighted market index. This is the standard market model, where, in general, the constant and slope parameter are denoted by Jensen's $\alpha$ and the market $\beta$, respectively. The parameter estimates are given in Panel $A$ of Table 6 . The table also contains the test results for the null hypotheses that $\alpha>0$ (one-sided) and $\beta \neq 1$ (two-sided). The results indicate that Jensen's $\alpha$ remains significantly positive for Portfolios 1 through 3 in Panel $A$ after correcting for market risk. The market $\beta \mathrm{s}$ are higher than 1, but only for Portfolio 4 the difference is significant. Our earlier conclusion on the absence of clear-cut excess returns in the Panels $B$ through $G$ of Table 2 remains unaltered if we correct for risk. All $\alpha$ s are negative, except for Portfolio 1 in Panels $F$ and $G$. Also for Panel $H$ conclusions remain similar. The risk-corrected return of $\alpha=0.30$ is statistically significant at the $10 \%$ level. It is the only statistical significant entry for $\alpha$ in the table besides Panel $A$. Again, $\alpha$ s in Panel $H$ gradually decline if the ex-ante predicted performance of the stocks is weaker. With a few exceptions, the $R^{2} \mathrm{~s}$ of the market model are generally relatively high, indicating that the model captures an important part of the variation in portfolio returns.

The market model is only one of the many potential risk models that explain returns differentials. The three factor model of Fama and French (1993) is another well-known model, see, e.g., Daniel and Titman (1997) and Lewellen (1999). The risk factors in this model are (i) a market return factor $\left(F F_{R m}\right)$, (ii) a return differential of a portfolio consisting of high $B / P$ stocks minus a portfolio of low $B / P$ stocks $\left(F F_{H M L}\right)$ and (iii) a return differential of a portfolio consisting of small stocks minus a portfolio consisting of big stocks $\left(F F_{S M B}\right)$. The latter two are orthogonal with respect to $F F_{R m}$. All these portfolios are equally weighted. The results in Panel A of Table 10 indicate that not only a market risk factor, but also the size and bookto-market risk factors capture variation in the portfolio returns. We test whether the factor loading of $F F_{R m}$ is different from one and whether the factor loadings of $F F_{H M L}$ and $F F_{S M B}$ are significantly different from zero. 
All three tests are two-sided. Tests on $F F_{\alpha}>0$ are again one-sided. Most parameter estimates in Panel $A$, including the risk-corrected returns $F F_{\alpha}$, are significant at the one percent level. The coefficient of determination ranges from 0.84 for Portfolio 1 to 0.95 for Portfolio 4, which suggests a good fit of the model. This is in accordance with expectations, as Panel $A$ assumes perfect foresight for the effects of the Size and B/P. Under less than perfect foresight, Panels $B$ through $F$ show that most $F F_{\alpha} \mathrm{s}$ are insignificant or negative. There are three exceptions with respect to significance. Investing in the $20 \%$ stocks with the highest $\mathrm{B} / \mathrm{P}$ values generated significant riskcorrected returns. Also Portfolio 2 of the Random Walk model leads to a significant $F F_{\alpha}$. Both of these did not show up under the alternative risk correction in Table 6. Finally, the top quintile (Portfolio 1) of the Business Cycle approach generates a statistically significant $F F_{\alpha}$. This is robust to the way of risk-correction, compare Table 6 . Note that both the Jensen's $\alpha$ s and the $F F_{\alpha}$ s for the Business Cycle model are substantially higher than those of the other models (excepting Panel $A$ ). Moreover, the coefficients of $F F_{S M B}$ and $F F_{H M L}$ differ substantially across models. We conclude that the Business Cycle method generates the best overall performance before and after risk correction. The difference between the perfect foresight setting and the other models remains relatively large. Hence, only a limited fraction of the variation in the effects of Size and $B / P$ can be forecasted by our approaches.

\section{B. Quarterly returns}

Table 3 provides the results when rebalancing takes place after a buy and hold period of three months. The methodology and structure of the tables for quarterly returns are similar to those for monthly returns. Panel $A$ of Table 3 shows that perfect (linear) forecasting skills with respect to Size and $B / M$ impact are highly rewarding for the three month investment horizon. The return on Portfolio 1, for example, is about 468 basis points higher than that on an equally-weighted portfolio. The average returns on Portfolios 2 through 4 are higher than that on the benchmark portfolio and gradually decline, while the return for Portfolio 5 falls short of the benchmark. The standard deviations of the portfolios are higher than that of the benchmark portfolio, and downside-risk measures are again increasing in the Portfolio number. The turnover indicator shows that 30.5 per cent of Portfolio 1 is not sold on average. This figure is lower for the other portfolios.

In Panels $B$ through $G$, none of the returns exceeds the benchmark return of 4.43. In Panel $H$, the return on Portfolio 1 clearly exceeds the benchmark. This is consistent with the earlier results for monthly data. Again, we also find a monotonic relation across the returns of five portfolios for the Business 
Cycle model. The only other method satisfying this criterion for quarterly data is the Random Walk method. Consistent with the monthly results, the standard deviation and lower partial moments for Panel $H$ as measures of risk decrease with the stated return: weaker predicted winners show weaker ex-post performance and higher risk.

As before, we also consider risk-corrected returns using both the the market model and the three factor Fama and French model. The results are in Tables 7 and 11, respectively. The Jensen's $\alpha$ s in Table 7 are positive for Portfolios 1 and 2 only in Panel A. Perfect foresight about the Size and BM would lead to significant average returns only for clear predicted winners. In the remaining panels, only Portfolio 1 for Panel $H$ generates a significantly positive Jensen's $\alpha$ s. This corroborates the results for monthly holding periods. The positive $\alpha$ comes with a market $\beta$ that is insignificantly below 1. By contrast, fixed BM and Size strategies (Panels $B$ and $C$ ) typically come with market $\beta$ s exceeding 1 . Table 11 gives the $F F_{\alpha} \mathrm{s}$. Panel $A$ illustrates that perfect foresight of the Size and $B M$ impact would lead to significantly positive risk-corrected returns for 4 out of 5 portfolios. Panels $B$ and $C$ show that for quarterly data we obtain the familiar pattern documented in the literature: high $\mathrm{B} / \mathrm{P}$ and small Size strategies outperform the benchmark after correcting for risk. The reported $F F_{\alpha} \mathrm{s}$ are, however, much lower than for the Business Cycle approach if we concentrate on the clearest predicted winners, i.e., Portfolio 1 for Panels B and $\mathrm{H}$ and Portfolio 5 for Panel C. Moreover, it is interesting to note that Panel $H$ now has two significant entries: the top $40 \%$ of predicted winner stocks generate significant risk-corrected performance. It is also interesting to see that the factor loadings are very different between the portfolios with significant $F F_{\alpha}$ s. The fixed BM and Size strategies come with market $\beta \mathrm{s}\left(F F_{R m}\right)$ of 1.05 and 1.21, respectively. These exceed unity. By contrast, the Business Cycle approach generates a market $\beta$ that is significantly below 1 . Also the loadings on the other risk factors, especially $F F_{S M B}$, differ substantially. The fit of the risk model for Portfolio 1 in Panel $H$ is not as good as for the fixed investment styles, suggesting that there may be another risk factor that is not accounted for in the FF framework.

\section{Semi-annual and annual returns}

Tables 4, 8, and 12 show return statistics and risk measures for portfolios that are actively rebalanced twice a year using one of our forecasting meth-

ods. Similarly, Tables 5, 9, and 13 present the results for annual holding periods. As before, the only modeling approach showing a consistent behavior across rebalancing periods and methods for risk-correction is the Business Cycle approach. The clear predicted winners (Portfolio 1 of Panel $H$ ) show 
significant excess return before and after risk-correction. Moreover, ex-post performance declines if the portfolio contains stocks with a weaker ex-ante predicted performance. Again, the market $\beta$ for Portfolio 1 in Panel $H$ is below unity.

\section{Synthesis and robustness}

We conclude from the previous analyses that a rotating Size and B/Pbased investment style based on a Business Cycle approach is able to generate significant excess returns. These returns are robust to the holding period of stocks and to the way of risk-correction. The more conventional fixed investment styles, like one based on small Sizes or high $\mathrm{B} / \mathrm{P}$ values, may also generate significant (risk-corrected) returns, but the results are not as robust to the way of risk-correction or the choice of holding period. Purely statistical approaches to style rotation are not very promising: they either underperform with respect to the benchmark, or the detected outperformance is offset by an increase in risk.

In order to check the robustness of the Business Cycle approach further, we also used a market-capitalization-weighted index. In addition, Portfolios 1 through 5 were constructed using market-capitalization weights. This is somewhat more in line with the way how portfolios are constructed in practice. The results (not reported here) are robust to this change. Clear predicted ex-ante winners using the Business Cycle approach generate significant excess returns, irrespective of the market model or FF way of risk correction. The results are consistent across holding periods, except for annual frequencies. For yearly rebalancing, the excess (risk-corrected) return is still positive, but insignificant. This may, however, be due purely to the limited number of annual observations (10) given our data set.

As indicated in Section 3, outliers may be a potential hazard in analyses with this type of data. In order to check for the sensitivity of the results to outliers, we cross-sectionally Winsorized Size and B/P values. This means that we define boundary values for each variable and cross section. The boundaries equal the cross-sectional median plus or minus four times a robustly estimated standard deviation. If an observation falls above the upper or below the lower boundary, respectively, it is reset to the boundary value. This mitigates the potential bias of outliers in a standard regression setting, see for example Hampel, Ronchetti, Rousseeuw, and Stahel (1986). The returns are not Winsorized. Again, the results are robust: clear predicted winners show a consistent and robust excess performance across holding periods and ways of risk-correction. 


\section{Concluding Remarks}

This paper develops a framework for capturing the time-varying impact of firm characteristics like size and book-to-price on excess returns. We showed that both the magnitude and direction of this impact displayed considerable time-variation. Using standard statistical techniques, however, did not help in predicting the future direction of impact. By contrast, by linking the impact to macroeconomic conditions through the term structure and business cycle leading indicator, we found significant and robust excess returns to porfolios of clear predicted winners. The returns were robust to various ways of risk-correction, choice of holding period, way of portfolio construction, and outlier control. Standard small-Size and high book-to-market investment strategies were not robust in this respect.

Our results add a further dimension to the current anomaly versus risk compensation debate for explaning reported excess returns from Size and book-to-market investment strategies. In particular, by allowing for rotating investment styles over time, we examine whether the excess returns are in effect the manifestation of a more dynamic asset pricing model. The robustness of the resulting excess returns on a rotating investment scheme that is consistent with such a dynamic asset pricing model, contrasts with the less robust patterns found for conventional Size and book-to-market investment strategies.

\section{Appendix A: Bias correction for Subsection 4.4}

Here we derive the bias correction for the autoregressive modeling approach of Subsection 4.4. Note that if we write $\hat{\gamma}_{t}=\gamma_{t}+\xi_{t}$ with $\xi_{t}$ and $\eta_{t}$ uncorrelated zero-mean random variables, one easily derives the following relations. For $\Phi$ we have

$$
\Phi=\operatorname{Cov}\left(\gamma_{t}, \gamma_{t-1}\right)\left[\operatorname{Cov}\left(\gamma_{t-1}\right)\right]^{-1} .
$$

By contrast, if $\hat{\Phi}$ is the parameter in the model with all $\gamma_{t}$ 's replaced by $\hat{\gamma}_{t}$ 's, we have

$$
\begin{aligned}
\hat{\Phi} & =\operatorname{Cov}\left(\hat{\gamma}_{t}, \hat{\gamma}_{t-1}\right)\left[\operatorname{Cov}\left(\hat{\gamma}_{t-1}\right)\right]^{-1} \\
& \approx \operatorname{Cov}\left(\gamma_{t}, \gamma_{t-1}\right)\left[\operatorname{Cov}\left(\gamma_{t-1}\right)+\bar{V}_{t-1}\right]^{-1} \\
& =\Phi \operatorname{Cov}\left(\gamma_{t-1}\right)\left[\operatorname{Cov}\left(\gamma_{t-1}\right)+\bar{V}_{t-1}\right]^{-1},
\end{aligned}
$$

where

$$
\bar{V}_{t-1}=\sum_{s=1}^{t-1} \operatorname{Cov}\left(\xi_{t}\right) /(t-1),
$$

Note that the persistency in $\gamma_{t}$ is generally under-estimated if $\Phi$ is estimated based on $\hat{\gamma}_{t}$. The numerators in (A1) and (A2) are the same, while the denominator in (A2) is larger. Note that $\xi_{t}$ can be interpreted as the estimation error of $\hat{\gamma}_{t}$. Using standard asymptotic theory, it follows that $n_{t}^{1 / 2}\left(\hat{\gamma}_{t}-\gamma_{t}\right)$ is (asymptotically) normally distributed with mean 
zero and covariance matrix $V_{t}$. Here, $n_{t}$ is the number of firms in cross-section $t$. The covariance matrix $V_{t}$ is estimated consistently by the OLS covariance matrix of $\hat{\gamma}_{t}$, and can be directly plugged into (A3). Using the estimates of $\bar{V}_{t-1}$ and $\hat{\Phi}_{t}$, we can rewrite (A2) to obtain the following bias-corrected estimate of $\Phi$,

$$
\tilde{\Phi}_{t}=\hat{\Phi} \operatorname{Cov}\left(\hat{\gamma}_{t-1}\right)\left[\operatorname{Cov}\left(\hat{\gamma}_{t-1}\right)-\bar{V}_{t-1}\right]^{-1},
$$

where we have used the equality $\operatorname{Cov}\left(\hat{\gamma}_{t-1}\right)=\operatorname{Cov}\left(\gamma_{t-1}\right)+\bar{V}_{t-1}$ to subsitute the unobserved $\operatorname{Cov}\left(\gamma_{t-1}\right)$ by the observed $\operatorname{Cov}\left(\hat{\gamma}_{t-1}\right)-\bar{V}_{t-1}$. Note that the estimate $\tilde{\Phi}_{t}$ of $\Phi$ depends on $t$, i.e., on the time the forecast is made. This implies that the parameter estimates of the autoregressive model (A1) are updated recursively as the forecasting period progresses. Given $\tilde{\Phi}$, the constant term in (7) is estimated as

$$
\tilde{\mu}_{t}=\sum_{s=1}^{t-1}\left(\hat{\gamma}_{s}-\tilde{\Phi}_{t} \hat{\gamma}_{s-1}\right) /(t-1)
$$

Also note that the bias correction is quite small if the cross-sectional dimension is sufficiently large. This is due to the fact that the cross-sectional estimators are consistent, such that the measurement error problem and associated bias disappear if the cross-sectional dimension grows indefinitely. 


\section{References}

Barber Brad. M. and John D. Lyon, 1997, Firm-size, book-to-market-ratio, and security returns: A holdout sample of financial firms, Journal of Finance 52, 875-883.

Black, Fischer, 1993, Beta and return, Journal of Portfolio Management 20, 8-18.

Chan, K,C. Louis, Jason Karceski and Josef Lakonishok, 1999, A new paradigma or the same old hype?: the future of value versus growth investing. Working paper.

Chen, Nai-fu, 1991, Financial investment opportunities and the macroeconomy, Journal of Finance 46, 529-554.

Chen, Nai-fu, Richard Roll, and Stephen A. Ross, 1986, Economic forces and the stock market, Journal of Business 59, 383-404.

Cowles, A., and H. Jones, 1937, Some a posteriori probabilities in stock market action, Econometrica 5, 280-294.

Daniel, Kent and Sheridan Titman, 1997, Evidence on the characteristics of cross sectional variation in stock returns, Journal of Finance 52, 1-33.

Fama, Eugene F., and Kenneth French, 1992, The cross-section of expected stock returns, Journal of Finance 47, 427-466.

Fama, Eugene F., and Kenneth French, 1993, Common risk factors in the returns on stocks and bonds, Journal of Financial Economics 33, 3-56.

He, Jia, Raymond Kan, Lilian Ng and Chu Zhang, 1996, Tests of the relations among marketwide factors, firm-specific variables and stock returns using a conditional asset pricing model, The Journal of Finance 51, 1891-1908.

Hampel, Frank M., Elvezio M. Ronchetti, Peter J. Rousseeuw, and Werner A. Stahel, 1986, Robust statistics. The approach based on influence functions, New York: Wiley.

Jensen, Gerald R., Robert R. Johnson and Jeffrey M. Mercer, 1996, Business conditions, monetary policy and expected security returns, Journal of Financial Economics 40, $213-237$.

Jensen, Gerald R., Robert R. Johnson and Jeffrey M. Mercer, 1997, New evidence on size and price-to-book effect in stock returns, Financial Analysts Journal, 34-42.

Jorion, Philippe, 1996, Value-at-Risk: the new benchmark for controling market risk, Chicago: Irwin.

Lakonishok, Josef, Andrei Shleifer, and Robert W. Vishny, 1994, Contrarian investment, extrapolation, and risk, Journal of Finance 49, 1541-1578.

La Porta, Rafael, 1996, Expectations and the cross-section of stock returns, Journal of Finance 51, 1715-1742.

Lewellen, Jonathan, 1999, The time-series relations among expected return, risk and book-to-market, Journal of Financial Economics 54, 5-43.

Lo, A. MacKinlay A.C., 1990, Data-snooping biases in tests of financial asset pricing models, Review of Financial Studies 3, 431-467. 
MacKinlay, A. Craig, 1995, Distinguishing among asset pricing theories: An ex-ante analysis, Journal of Financial Economics 38, 3-28.

Pesaran, M. Hachem, and Allen Timmermann, 1994, Forecasting stock returns; an examination of stock market trading in the presence of transaction costs, Journal of Forecasting 13, 335-367.

Pesaran, M. Hachem, and Allen Timmermann, 1995, Predictability of stock returns: robustness and economic significance, Journal of Finance 50, 1201-1228.

Roll, Richard, 1992, A mean/variance analysis of tracking error, Journal of Portfolio Management, 13-22.

Rosenberg, Barr, 1974, Extra-market components of covariance in security returns, Journal of Financial and Quantitative Analysis 9, 263-273.

Schwert, G. William, 1990, Stock returns and real activity: a century of evidence, Journal of Finance 45, 1237-1257. 
Table 2: Investment Results from Monthly Return Factor Models

\begin{tabular}{lrrrrrrrrrrr}
\hline \hline & \multicolumn{4}{c}{ Panel A: Perfect foresight } & \multicolumn{4}{c}{ Panel B: Fixed BM method } \\
Quintile & 1 & 2 & 3 & 4 & 5 & 1 & 2 & 3 & 4 & 5 \\
Performance & 3.27 & 2.52 & 2.14 & 1.72 & 1.34 & 1.27 & 1.20 & 0.97 & 1.03 & 1.21 \\
Standard Deviation & 5.26 & 4.80 & 4.78 & 4.90 & 4.84 & 5.08 & 4.13 & 4.40 & 4.88 & 5.93 \\
Tracking Error & 3.25 & 2.53 & 2.60 & 2.51 & 2.58 & 3.52 & 2.23 & 2.17 & 2.35 & 3.32 \\
Turnover Indicator & 32.4 & 27.2 & 25.3 & 24.5 & 28.8 & 83.7 & 75.3 & 74.4 & 78.8 & 86.6 \\
$0^{\text {th }}$ order lower partial moment & 0.21 & 0.35 & 0.44 & 0.49 & 0.55 & 0.55 & 0.50 & 0.57 & 0.58 & 0.51 \\
$1^{\text {st }}$ order lower partial moment & 0.06 & 0.32 & 0.55 & 0.77 & 1.02 & 1.23 & 0.89 & 1.05 & 1.12 & 1.39 \\
$2^{\text {nd }}$ order lower partial moment & 0.04 & 0.46 & 1.14 & 2.15 & 3.08 & 5.03 & 2.82 & 2.96 & 3.39 & 6.14
\end{tabular}

Quintile

Performance

Standard Deviation

Tracking Error

Turnover Indicator

$0^{\text {th }}$ order lower partial moment

$1^{\text {st }}$ order lower partial moment

$2^{\text {nd }}$ order lower partial moment

Panel C: Fixed Size method

$\begin{array}{rrrrr}1 & 2 & 3 & 4 & 5 \\ 1.33 & 1.20 & 1.11 & 1.05 & 0.97 \\ 3.97 & 4.59 & 5.00 & 5.19 & 5.84 \\ 0.74 & 2.02 & 2.72 & 3.15 & 4.28 \\ 93.3 & 87.0 & 81.4 & 78.3 & 81.8 \\ 0.55 & 0.55 & 0.55 & 0.60 & 0.61 \\ 0.31 & 0.90 & 1.22 & 1.39 & 1.78 \\ 0.33 & 2.33 & 4.13 & 5.21 & 8.26\end{array}$

Panel E: Averaging method
Quintile

Performance

Standard Deviation

Tracking Error

Turnover Indicator

$0^{\text {th }}$ order lower partial moment

$1^{\text {st }}$ order lower partial moment

$2^{\text {nd }}$ order lower partial moment

\begin{tabular}{|c|c|c|c|c|}
\hline 1 & 2 & 3 & 4 & \\
\hline 1.39 & 1.33 & 1.21 & 1.25 & 1.1 \\
\hline 3.82 & 4.15 & 4.33 & 4.54 & 4.7 \\
\hline 75 & 1.28 & 1.72 & 2.09 & 2. \\
\hline .7 & 80.8 & 74.1 & 68.4 & 64 \\
\hline 0.58 & 0.53 & 0.60 & 0.54 & 0.5 \\
\hline 31 & 0.52 & 0.74 & 0.88 & 1.1 \\
\hline (2) & 0.94 & 1.58 & 2.31 & 3. \\
\hline
\end{tabular}

Quintile

Performance

Standard Deviation

Tracking Error

Turnover Indicator

$0^{\text {th }}$ order lower partial moment

$1^{\text {st }}$ order lower partial moment

$2^{\text {nd }}$ order lower partial moment
Panel G: Random walk method

\begin{tabular}{rrrrrrrrrrr}
\multicolumn{3}{c}{ Panel G: Random walk method } & \multicolumn{4}{c}{ Panel H: Business cycle method } \\
1 & 2 & 3 & 4 & 5 & 1 & 2 & 3 & 4 & 5 \\
1.42 & 1.37 & 1.32 & 1.16 & 1.15 & 1.70 & 1.48 & 1.32 & 1.21 & 1.16 \\
4.67 & 4.45 & 4.61 & 4.70 & 4.91 & 4.41 & 4.39 & 4.55 & 4.71 & 4.82 \\
2.85 & 2.42 & 2.46 & 2.40 & 2.54 & 2.33 & 2.03 & 2.08 & 2.32 & 2.60 \\
33.3 & 27.6 & 25.7 & 24.5 & 29.9 & 73.9 & 62.6 & 58.0 & 55.2 & 53.0 \\
0.53 & 0.52 & 0.50 & 0.53 & 0.55 & 0.49 & 0.50 & 0.58 & 0.59 & 0.58 \\
0.87 & 0.89 & 0.99 & 1.09 & 1.13 & 0.54 & 0.72 & 0.83 & 0.98 & 1.15 \\
3.45 & 2.76 & 3.05 & 3.34 & 3.55 & 1.64 & 1.74 & 1.96 & 2.94 & 3.62 \\
\hline
\end{tabular}

Panel F: Autoregressive method

$\begin{array}{rrrrr}1 & 2 & 3 & 4 & 5 \\ 1.47 & 1.35 & 1.32 & 1.20 & 1.11 \\ 4.09 & 4.20 & 4.34 & 4.67 & 4.79 \\ 1.56 & 1.63 & 1.90 & 2.19 & 2.56 \\ 56.8 & 46.2 & 41.5 & 37.7 & 36.8 \\ 0.55 & 0.52 & 0.52 & 0.50 & 0.55 \\ 0.49 & 0.64 & 0.75 & 0.97 & 1.15 \\ 0.99 & 1.36 & 1.79 & 2.77 & 3.47\end{array}$

Panel H: Business cycle method

Note: This table contains return and risk statistics for several investment strategies. Each month, we construct five equally weighted portfolios given the return forecasts that we obtain from factor models. The portfolios contain only stocks for which the return forecasts are positive. We use Size and book-to-market ratios as factors. The factor loadings differ across the models. Each month we estimate the factor models using extending samples from June 1984 onwards. We make the first forecasts in June 1989. Panel A gives the results if we have perfect foresight on the factor loadings of Size and book-to-market. Panels B and $\mathrm{C}$ show the findings relating to a value and a large cap investment style, respectively. Panels $\mathrm{D}$ through $\mathrm{G}$ show results obtained from time-dependent models for the factor loadings, and Panel $\mathrm{H}$ makes use of macroeconomic variables to model the dynamics in the factor loadings. The average and the standard deviation of the equally weighted market inglgx (benchmark) are 1.42 and 3.86, respectively. 
Table 3: Investment Results from Quarterly Return Factor Models

\begin{tabular}{|c|c|c|c|c|c|c|c|c|c|c|}
\hline \multirow[b]{2}{*}{ Quintile } & \multicolumn{5}{|c|}{ Panel A: Perfect foresight } & \multicolumn{5}{|c|}{ Panel B: Fixed BM method } \\
\hline & 1 & 2 & 3 & 4 & 5 & 1 & 2 & 3 & 4 & 5 \\
\hline Performance & 9.11 & 6.64 & 6.01 & 4.89 & 3.50 & 4.26 & 3.83 & 3.41 & 3.35 & 4.03 \\
\hline Standard Deviation & 11.64 & 10.05 & 9.69 & 10.21 & 9.50 & 11.33 & 8.57 & 8.63 & 9.72 & 11.76 \\
\hline Tracking Error & 8.11 & 6.01 & 5.57 & 5.38 & 4.81 & 8.47 & 4.90 & 4.39 & 4.99 & 6.56 \\
\hline Indicator & 30.5 & 24.6 & 22.1 & 20.3 & 23.5 & 70.6 & 59.9 & 58.5 & 64.1 & 75.6 \\
\hline $0^{t h}$ order lower partial moment & 0.15 & 0.42 & 0.45 & 0.53 & 0.65 & 0.57 & 0.60 & 0.60 & 0.57 & 0.47 \\
\hline $1^{s t}$ order lower partial moment & 0.09 & 0.79 & 1.02 & 1.60 & 2.27 & 2.90 & 2.03 & 2.17 & 2.45 & 2.68 \\
\hline \multirow[t]{2}{*}{$2^{\text {nd }}$ order lower partial moment } & 0.09 & 2.06 & 3.92 & 8.44 & 13.82 & 23.96 & 12.36 & 11.99 & 16.12 & 22.72 \\
\hline & \multicolumn{5}{|c|}{ Panel C: Fixed Size method } & \multicolumn{5}{|c|}{ Panel D: Pooling method } \\
\hline Quintile & 1 & 2 & 3 & 4 & 5 & 1 & 2 & 3 & 4 & \\
\hline Perfor & 4.17 & 3.77 & 3.45 & 3.37 & 4.12 & 3.79 & 3.56 & 3.91 & 3.36 & 3.48 \\
\hline Stanc & 6.97 & 8.82 & 9.89 & 10.89 & 12.97 & 6.85 & 7.24 & 8.08 & 8.84 & 9.66 \\
\hline Tracl & 1.20 & 4.09 & 5.18 & 6.98 & 9.56 & 2.00 & 2.58 & 3.49 & 4.21 & 5.40 \\
\hline Turs & 87.8 & 76.8 & 67.6 & 62.2 & 65.2 & 64.1 & 54.9 & 49.7 & 45.3 & 41.4 \\
\hline tial moment & 0.57 & 0.60 & 0.60 & 0.60 & 0.63 & 0.63 & 0.60 & 0.55 & 0.55 & 0.57 \\
\hline $1^{s t}$ order lower partial moment & 0.63 & 1.88 & 2.46 & 3.17 & 3.57 & 1.04 & 1.54 & 1.61 & 2.24 & 2.53 \\
\hline \multirow[t]{2}{*}{$2^{\text {nd }}$ order lower partial moment } & 0.96 & 9.16 & 15.50 & 24.43 & 30.17 & 3.29 & 5.36 & 6.39 & 11.71 & 16.98 \\
\hline & \multicolumn{5}{|c|}{ Panel E: Averaging method } & \multicolumn{5}{|c|}{ Panel F: Autoregressive method } \\
\hline Quintile & 1 & 2 & 3 & 4 & 5 & 1 & 2 & 3 & 4 & 0 \\
\hline Perf & 4.16 & 4.00 & 3.77 & 3.95 & 3.56 & 3.37 & 3.31 & 3.83 & 3.42 & 3.42 \\
\hline Stan & 6.81 & 7.05 & 7.60 & 9.06 & 8.94 & 10.67 & 8.73 & 9.44 & 9.30 & 9.71 \\
\hline Trac & 2.81 & 2.83 & 3.48 & 4.36 & 4.94 & 7.72 & 5.01 & 5.71 & 4.99 & 5.40 \\
\hline Tur & 62.0 & 45.2 & 38.3 & 33.2 & 30.8 & 34.1 & 24.6 & 21.7 & 21.6 & 22.0 \\
\hline $0^{t h}$ & 0.57 & 0.50 & 0.65 & 0.63 & 0.63 & 0.57 & 0.53 & 0.63 & 0.65 & 0.57 \\
\hline $1^{\text {st }}$ order lower partial moment & 1.14 & 1.31 & 1.65 & 1.81 & 2.32 & 3.04 & 2.44 & 2.34 & 2.43 & 2.51 \\
\hline \multirow[t]{2}{*}{$2^{\text {nd }}$ order lower partial moment } & 4.16 & 4.89 & 6.35 & 9.91 & 13.18 & 37.07 & 16.13 & 15.48 & 15.44 & 17.11 \\
\hline & \multicolumn{5}{|c|}{ Panel G: Random walk method } & \multicolumn{5}{|c|}{ Panel H: Business cycle method } \\
\hline Quint & 1 & 2 & 3 & 4 & 5 & 1 & 2 & 3 & 4 & 0 \\
\hline Performa & 3.82 & 3.47 & 3.43 & 3.38 & 3.35 & 5.38 & 4.17 & 3.98 & 3.63 & 3.39 \\
\hline Deviation & 8.75 & 8.32 & 8.83 & 9.60 & 9.51 & 7.85 & 8.05 & 8.81 & 9.46 & 9.94 \\
\hline Tracking Error & 4.30 & 3.40 & 4.12 & 5.03 & 5.06 & 5.72 & 4.83 & 4.60 & 5.15 & 5.55 \\
\hline Turnover Indicator & 33.9 & 28.3 & 25.0 & 22.8 & 26.1 & 62.6 & 51.6 & 46.2 & 42.6 & 41.7 \\
\hline $0^{t h}$ order lower partial $n$ & 0.53 & 0.65 & 0.60 & 0.65 & 0.63 & 0.45 & 0.63 & 0.65 & 0.63 & 0.68 \\
\hline $1^{s t}$ order lower partial moment & 1.67 & 1.87 & 2.15 & 2.45 & 2.56 & 0.99 & 1.79 & 1.90 & 2.29 & 2.59 \\
\hline $2^{\text {nd }}$ order lower partial moment & 12.24 & 8.79 & 11.58 & 14.90 & 15.76 & 5.79 & 8.69 & 8.94 & 13.41 & 16.85 \\
\hline
\end{tabular}

Note: This table contains return and risk statistics for several investment strategies. Each three months, we construct five equally weighted portfolios given the return forecasts that we obtain from factor models. The portfolios contain only stocks for which the return forecasts are positive. We use Size and book-to-market ratios as factors. The factor loadings differ across the models. Each month we estimate the factor models using extending samples from June 1984 onwards. We make the first forecasts in June 1989. Panel A gives the results if we have perfect foresight on the factor loadings of Size and book-to-market. Panels B and C show the findings relating to a value and a large cap investment style, respectively. Panels D through $\mathrm{G}$ show results obtained from time-dependent models for the factor loadings, and Panel $\mathrm{H}$ makes use of macroeconomic variables to model the dynamics in the factor loadings. The average and the standard deviation of the equally weighted market index (benchmark) are 4.43 and 6.75 , respectively. 
Table 4: Investment Results from Semi-Annual Return Factor Models

\begin{tabular}{|c|c|c|c|c|c|c|c|c|c|c|}
\hline \multirow[b]{2}{*}{ Quintile } & \multicolumn{5}{|c|}{ Panel A: Perfect foresight } & \multicolumn{5}{|c|}{ Panel B: Fixed BM method } \\
\hline & 1 & 2 & 3 & 4 & 5 & 1 & 2 & 3 & 4 & 5 \\
\hline Performance & 19.0 & 11.4 & 9.61 & 8.17 & 7.31 & 8.83 & 7.48 & 6.98 & 6.86 & 7.74 \\
\hline Standard Deviation & 16.48 & 9.86 & 9.13 & 10.29 & 10.12 & 14.72 & 10.12 & 9.44 & 9.70 & 13.00 \\
\hline Tracking Error & 14.42 & 7.30 & 6.19 & 7.11 & 7.03 & 12.58 & 7.16 & 5.93 & 5.94 & 8.42 \\
\hline Turnover Indicator & 10.2 & 10.0 & 9.0 & 9.4 & 15.8 & 59.9 & 48.8 & 46.9 & 52.4 & 64.7 \\
\hline $0^{t h}$ order lower partial moment & 0.05 & 0.45 & 0.45 & 0.65 & 0.60 & 0.40 & 0.55 & 0.65 & 0.65 & 0.50 \\
\hline $1^{\text {st }}$ order lower partial moment & 0.06 & 1.34 & 1.81 & 2.94 & 3.60 & 4.54 & 3.38 & 3.29 & 3.39 & 4.08 \\
\hline \multirow[t]{2}{*}{$2^{\text {nd }}$ order lower partial moment } & 0.07 & 6.63 & 11.76 & 25.68 & 33.74 & 74.74 & 34.44 & 28.78 & 25.73 & 41.84 \\
\hline & \multicolumn{5}{|c|}{ Panel C: Fixed Size method } & \multicolumn{5}{|c|}{ Panel D: Pooling method } \\
\hline Quintile & 1 & 2 & 3 & 4 & 5 & 1 & 2 & 3 & 4 & \\
\hline Performance & 8.12 & 7.20 & 6.21 & 5.77 & 10.6 & 7.39 & 6.81 & 7.26 & 6.39 & 7.40 \\
\hline Stan & 7.13 & 8.95 & 10.56 & 11.97 & 17.12 & 13.58 & 11.21 & 10.53 & 9.97 & 10.26 \\
\hline Tracl & 1.75 & 5.37 & 7.21 & 8.05 & 14.46 & 10.09 & 7.26 & 7.11 & 7.26 & 7.37 \\
\hline Turn & 82.4 & 68.0 & 56.0 & 48.7 & 50.8 & 38.5 & 28.4 & 24.8 & 25.7 & 29.0 \\
\hline $0^{t h} \mathrm{o}$ & 0.65 & 0.55 & 0.70 & 0.70 & 0.45 & 0.40 & 0.60 & 0.55 & 0.55 & 0.65 \\
\hline $1^{\text {st }}$ order lower partial moment & 1.13 & 2.77 & 4.11 & 4.64 & 4.27 & 4.14 & 4.13 & 3.52 & 4.13 & 3.62 \\
\hline \multirow[t]{2}{*}{$2^{\text {nd }}$ order lower partial moment } & 2.80 & 22.59 & 42.69 & 55.42 & 66.75 & 71.95 & 39.09 & 38.24 & 43.91 & 35.85 \\
\hline & \multicolumn{5}{|c|}{ Panel E: Averaging method } & \multicolumn{5}{|c|}{ Panel F: Autoregressive method } \\
\hline Quin & 1 & 2 & 3 & 4 & 5 & 1 & 2 & 3 & 4 & \\
\hline Perf & 9.30 & 8.41 & 7.45 & 7.39 & 6.86 & 12.9 & 9.82 & 8.41 & 7.98 & 6.92 \\
\hline Stan & 13.03 & 9.60 & 10.07 & 10.95 & 10.39 & 15.21 & 11.64 & 9.44 & 10.43 & 10.13 \\
\hline Track & 12.40 & 7.51 & 7.31 & 6.74 & 6.95 & 12.10 & 8.45 & 6.79 & 7.22 & 6.70 \\
\hline Tur & 36.8 & 23.4 & 18.1 & 17.9 & 17.2 & 32.4 & 19.8 & 16.9 & 16.1 & 17.2 \\
\hline $0^{t h} \mathrm{C}$ & 0.50 & 0.45 & 0.55 & 0.50 & 0.65 & 0.40 & 0.55 & 0.55 & 0.50 & 0.65 \\
\hline $1^{s t}$ order lower partial moment & 4.20 & 3.08 & 3.50 & 3.27 & 3.61 & 1.71 & 2.37 & 2.50 & 3.08 & 3.60 \\
\hline \multirow[t]{2}{*}{$2^{\text {nd }}$ order lower partial moment } & 76.62 & 37.49 & 39.43 & 33.42 & 34.43 & 26.99 & 21.46 & 25.18 & 31.05 & 32.20 \\
\hline & \multicolumn{5}{|c|}{ Panel G: Random walk method } & \multicolumn{5}{|c|}{ Panel H: Business cycle method } \\
\hline Quintile & 1 & 2 & 3 & 4 & 5 & 1 & 2 & 3 & 4 & 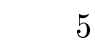 \\
\hline Performa & 6.82 & 6.93 & 6.63 & 5.98 & 6.10 & 12.2 & 9.31 & 7.26 & 6.24 & 5.54 \\
\hline Stan & 11.78 & 10.44 & 10.58 & 10.07 & 10.54 & 10.14 & 9.20 & 9.31 & 9.48 & 10.21 \\
\hline Tracking Error & 7.80 & 5.78 & 5.98 & 6.42 & 7.12 & 9.37 & 6.13 & 4.98 & 5.97 & 6.89 \\
\hline Turnover Indicator & 15.0 & 12.6 & 11.2 & 12.9 & 20.7 & 39.7 & 30.6 & 26.1 & 25.3 & 25.0 \\
\hline $0^{t h}$ order lower partial $\mathrm{r}$ & 0.55 & 0.65 & 0.80 & 0.70 & 0.65 & 0.45 & 0.55 & 0.60 & 0.75 & 0.65 \\
\hline $1^{\text {st }}$ order lower partial moment & 3.31 & 3.17 & 3.52 & 4.00 & 4.29 & 1.09 & 2.10 & 2.75 & 3.83 & 4.82 \\
\hline $2^{n d}$ order lower partial moment & 49.77 & 29.67 & 28.25 & 38.76 & 42.84 & 8.93 & 13.86 & 18.97 & 32.72 & 44.86 \\
\hline
\end{tabular}

Note: This table contains return and risk statistics for several investment strategies. Each six months, we construct five equally weighted portfolios given the return forecasts that we obtain from factor models. The portfolios contain only stocks for which the return forecasts are positive. We use Size and book-to-market ratios as factors. The factor loadings differ across the models. Each month we estimate the factor models using extending samples from June 1984 onwards. We make the first forecasts in June 1989. Panel A gives the results if we have perfect foresight on the factor loadings of Size and book-to-market. Panels B and C show the findings relating to a value and a large cap investment style, respectively. Panels D through $\mathrm{G}$ show results obtained from time-dependent models for the factor loadings, and Panel $\mathrm{H}$ makes use of macroeconomic variables to model the dynamics in the factor loadings. The average and the standard deviation of the equally weighted market index (benchmark) are 8.82 and 7.20 , respectively. 
Table 5: Investment Results from Annual Return Factor Models

\begin{tabular}{|c|c|c|c|c|c|c|c|c|c|c|}
\hline \multirow[b]{2}{*}{ Quintile } & \multicolumn{5}{|c|}{ Panel A: Perfect foresight } & \multicolumn{5}{|c|}{ Panel B: Fixed BM method } \\
\hline & 1 & 2 & 3 & 4 & 5 & 1 & 2 & 3 & 4 & 5 \\
\hline Performance & 36.5 & 25.4 & 17.5 & 15.4 & 14.3 & 18.5 & 15.9 & 16.8 & 17.3 & 19.4 \\
\hline Standard Deviation & 13.53 & 12.31 & 13.47 & 10.39 & 12.45 & 13.83 & 11.73 & 10.06 & 7.95 & 13.61 \\
\hline Tracking Error & 13.11 & 10.61 & 8.45 & 8.06 & 8.90 & 12.82 & 9.20 & 8.61 & 5.34 & 10.52 \\
\hline Indicator & 13.8 & 13.3 & 15.4 & 16.4 & 16.4 & 48.3 & 40.8 & 37.9 & 43.4 & 52.3 \\
\hline rtial moment & 0.00 & 0.30 & 0.50 & 0.70 & 0.70 & 0.60 & 0.50 & 0.60 & 0.60 & 0.50 \\
\hline $1^{s t}$ order lower partial moment & 0.00 & 1.42 & 4.09 & 4.83 & 5.65 & 4.62 & 4.69 & 4.23 & 2.75 & 3.14 \\
\hline \multirow[t]{2}{*}{$2^{\text {nd }}$ order lower partial moment } & 0.00 & 8.14 & 39.49 & 49.36 & 73.23 & 79.69 & 62.50 & 40.28 & 19.21 & 55.93 \\
\hline & \multicolumn{5}{|c|}{ Panel C: Fixed Size method } & \multicolumn{5}{|c|}{ Panel D: Pooling method } \\
\hline Quintile & 1 & 2 & 3 & 4 & 5 & 1 & 2 & 3 & 4 & \\
\hline Perfor & 17.0 & 14.6 & 12.6 & 13.5 & 30.0 & 26.0 & 20.2 & 17.7 & 14.4 & 13.9 \\
\hline Stan & 8.24 & 9.42 & 8.33 & 11.83 & 14.32 & 13.85 & 12.74 & 13.51 & 10.37 & 11.73 \\
\hline Tracl & 2.77 & 7.19 & 7.29 & 8.67 & 12.90 & 10.78 & 11.04 & 10.65 & 7.07 & 9.78 \\
\hline Tur & 79.1 & 62.0 & 50.0 & 41.8 & 40.5 & 33.4 & 23.5 & 18.9 & 18.3 & 20.7 \\
\hline ial moment & 0.70 & 0.90 & 0.80 & 0.90 & 0.20 & 0.20 & 0.50 & 0.50 & 0.90 & 0.70 \\
\hline $1^{s t}$ order lower partial moment & 1.98 & 4.96 & 6.69 & 6.22 & 1.25 & 1.22 & 3.48 & 4.43 & 5.10 & 6.28 \\
\hline \multirow[t]{2}{*}{$2^{\text {nd }}$ order lower partial moment } & 7.05 & 49.52 & 77.59 & 75.38 & 10.27 & 8.76 & 33.45 & 60.18 & 50.68 & 83.84 \\
\hline & \multicolumn{5}{|c|}{ Panel E: Averaging method } & \multicolumn{5}{|c|}{ Panel F: Autoregressive method } \\
\hline Quintile & 1 & 2 & 3 & 4 & 5 & 1 & 2 & 3 & 4 & \\
\hline Perf & 23.3 & 20.4 & 16.5 & 16.3 & 17.8 & 23.0 & 18.0 & 16.5 & 13.8 & 13.3 \\
\hline Stan & 15.14 & 12.23 & 11.94 & 12.91 & 13.37 & 19.72 & 12.98 & 11.66 & 9.78 & 7.41 \\
\hline Trac & 13.97 & 9.68 & 11.07 & 10.14 & 10.82 & 16.72 & 10.19 & 8.83 & 6.98 & 6.81 \\
\hline & 34.0 & 20.8 & 16.5 & 16.0 & 14.2 & 22.1 & 16.6 & 16.2 & 18.5 & 20.5 \\
\hline $0^{t h}$ & 0.30 & 0.30 & 0.60 & 0.60 & 0.60 & 0.40 & 0.50 & 0.60 & 0.70 & 0.70 \\
\hline $1^{\text {st }}$ order lower partial moment & 3.03 & 2.48 & 5.05 & 5.21 & 4.25 & 3.25 & 4.05 & 4.33 & 5.30 & 5.95 \\
\hline \multirow[t]{2}{*}{$2^{\text {nd }}$ order lower partial moment } & 53.09 & 30.75 & 71.34 & 64.37 & 50.47 & 55.19 & 62.87 & 53.91 & 62.41 & 64.95 \\
\hline & \multicolumn{5}{|c|}{ Panel G: Random walk method } & \multicolumn{5}{|c|}{ Panel H: Business cycle method } \\
\hline Quin & 1 & 2 & 3 & 4 & 5 & 1 & 2 & 3 & 4 & \\
\hline Performa & 32.5 & 23.2 & 17.0 & 13.9 & 12.9 & 27.5 & 20.5 & 17.0 & 15.2 & 13.6 \\
\hline Stanc & 16.43 & 14.08 & 11.15 & 11.08 & 9.45 & 15.75 & 12.08 & 9.77 & 10.38 & 10.77 \\
\hline Tracking Error & 15.65 & 12.27 & 9.33 & 8.18 & 8.13 & 15.12 & 9.38 & 7.50 & 7.73 & 8.23 \\
\hline Turnover Indicator & 16.2 & 14.9 & 14.4 & 14.4 & 15.2 & 25.0 & 16.6 & 14.0 & 11.9 & 14.1 \\
\hline $0^{t h}$ order lower partia & 0.30 & 0.50 & 0.50 & 0.80 & 0.70 & 0.30 & 0.60 & 0.50 & 0.80 & 0.60 \\
\hline $1^{s t}$ order lower partial moment & 0.96 & 2.68 & 4.07 & 5.81 & 6.78 & 1.18 & 2.69 & 3.78 & 4.81 & 5.94 \\
\hline $2^{\text {nd }}$ order lower partial moment & 4.79 & 25.10 & 52.15 & 66.60 & 82.76 & 8.86 & 17.71 & 32.77 & 45.12 & 78.25 \\
\hline
\end{tabular}

Note: This table contains return and risk statistics for several investment strategies. Each twelve months, we construct five equally weighted portfolios given the return forecasts that we obtain from factor models. The portfolios contain only stocks for which the return forecasts are positive. We use Size and book-to-market ratios as factors. The factor loadings differ across the models. Each month we estimate the factor models using extending samples from June 1984 onwards. We make the first forecasts in June 1989. Panel A gives the results if we have perfect foresight on the factor loadings of Size and book-to-market. Panels B and C show the findings relating to a value and a large cap investment style, respectively. Panels D through G show results obtained from time-dependent models for the factor loadings, and Panel $\mathrm{H}$ makes use of macroeconomic variables to model the dynamics in the factor loadings. The average and the standard deviation of the equally weighted market index (benchmark) are 18.5 and 9.58 , respectively. 
Table 6: Monthly Risk Analysis: Market Risk Model

\begin{tabular}{|c|c|c|c|c|c|c|c|c|c|c|}
\hline \multirow[b]{2}{*}{ Quintile } & \multicolumn{5}{|c|}{$\begin{array}{l}\text { Panel A: Perfect foresight } \\
\end{array}$} & \multicolumn{5}{|c|}{$\overline{\text { Panel B: Fixed BM method }}$} \\
\hline & 1 & 2 & 3 & 4 & 5 & 1 & 2 & 3 & 4 & 5 \\
\hline Jensen's $\alpha$ & $1.77^{a}$ & $1.03^{a}$ & $0.67^{a}$ & 0.19 & -0.14 & -0.12 & -0.14 & -0.45 & -0.51 & -0.52 \\
\hline Market $\beta$ & 1.08 & 1.06 & 1.04 & $1.10^{c}$ & 1.07 & 0.96 & $0.91^{c}$ & 1.00 & $1.12^{b}$ & $1.31^{a}$ \\
\hline \multirow[t]{2}{*}{$\mathrm{R}^{2}$} & 0.62 & 0.73 & 0.71 & 0.75 & 0.72 & 0.53 & 0.72 & 0.76 & 0.78 & 0.73 \\
\hline & \multicolumn{5}{|c|}{ Panel C: Fixed Size method } & \multicolumn{5}{|c|}{ Panel D: Pooling method } \\
\hline Quintile & 1 & 2 & 3 & 4 & 5 & 1 & 2 & 3 & 4 & 5 \\
\hline Jensen's $\alpha$ & -0.10 & -0.30 & -0.40 & -0.45 & -0.49 & -0.02 & -0.13 & -0.19 & -0.26 & -0.32 \\
\hline Market $\beta$ & 1.01 & 1.07 & 1.09 & 1.08 & 1.04 & 0.98 & 1.01 & 1.04 & 1.05 & 1.03 \\
\hline $\mathrm{R}^{2}$ & 0.97 & 0.81 & 0.71 & 0.64 & 0.47 & 0.96 & 0.91 & 0.85 & 0.79 & 0.71 \\
\hline & \multicolumn{5}{|c|}{ Panel E: Averaging method } & \multicolumn{5}{|c|}{ Panel F: Autoregressive method } \\
\hline Quintile & 1 & 2 & 3 & 4 & 5 & 1 & 2 & 3 & 4 & 5 \\
\hline Jensen's $\alpha$ & -0.01 & -0.12 & -0.24 & -0.23 & -0.32 & 0.07 & -0.07 & -0.11 & -0.30 & -0.37 \\
\hline Market $\beta$ & 0.97 & 1.03 & 1.03 & 1.05 & 1.03 & 0.98 & 1.00 & 1.01 & 1.07 & 1.05 \\
\hline \multirow[t]{2}{*}{$\mathrm{R}^{2}$} & 0.96 & 0.91 & 0.84 & 0.79 & 0.71 & 0.85 & 0.85 & 0.81 & 0.79 & 0.72 \\
\hline & \multicolumn{5}{|c|}{ Panel G: Random walk method } & \multicolumn{5}{|c|}{ Panel H: Business cycle method } \\
\hline Quintile & 1 & 2 & 3 & 4 & 5 & 1 & 2 & 3 & 4 & 5 \\
\hline Jensen's $\alpha$ & 0.04 & -0.02 & -0.12 & -0.32 & -0.37 & $0.30^{c}$ & 0.05 & -0.16 & -0.28 & -0.32 \\
\hline Market $\beta$ & 0.96 & 0.97 & 1.01 & 1.05 & 1.10 & 0.97 & 1.01 & 1.05 & 1.07 & 1.06 \\
\hline $\mathrm{R}^{2}$ & 0.63 & 0.71 & 0.72 & 0.74 & 0.74 & 0.72 & 0.79 & 0.79 & 0.76 & 0.71 \\
\hline
\end{tabular}

Note: This table shows the results from the regression of monthly portfolio returns on a constant and returns on an equally-weighted market index. Estimates for the constant and slope parameters are denoted by Jensen's $\alpha$ and market $\beta$, respectively. The portfolio returns result from applying several forecasting methods. Panels A through $\mathrm{H}$ relate each to a particular method. The Portfolios $q, q=1, \ldots, 5$, are obtained after ranking the positive return forecasts from a particular method and dividing up into quintiles. Portfolio 1 is based on stocks with the strongest ex-ante predicted outperformance. Significance is denoted by superscripts at the $1 \%\left({ }^{a}\right), 5 \%\left({ }^{b}\right)$, and $10 \%\left({ }^{c}\right)$ level, where we use a one-sided test for $\alpha>0$ and a two-sided test for $\beta \neq 1$. The symbol $R^{2}$ denotes the coefficient of determination. 
Table 7: Quarterly Risk Analysis: Market Risk Model

\begin{tabular}{|c|c|c|c|c|c|c|c|c|c|c|}
\hline \multirow[b]{2}{*}{ Quintile } & \multicolumn{5}{|c|}{ Panel A: Perfect foresight } & \multicolumn{5}{|c|}{ Panel B: Fixed BM method } \\
\hline & 1 & 2 & 3 & 4 & 5 & 1 & 2 & 3 & 4 & 5 \\
\hline Jensen's $\alpha$ & $3.81^{a}$ & $1.51^{c}$ & 0.95 & -0.62 & -1.73 & -0.63 & -0.78 & -1.39 & -1.95 & -2.16 \\
\hline Market $\beta$ & 1.27 & 1.22 & 1.19 & $1.34^{a}$ & $1.25^{b}$ & 1.14 & 1.06 & 1.12 & $1.27^{b}$ & $1.55^{a}$ \\
\hline \multirow[t]{2}{*}{$\mathrm{R}^{2}$} & 0.54 & 0.66 & 0.69 & 0.77 & 0.78 & 0.45 & 0.68 & 0.75 & 0.77 & 0.79 \\
\hline & \multicolumn{5}{|c|}{ Panel C: Fixed Size method } & \multicolumn{5}{|c|}{ Panel D: Pooling method } \\
\hline Quintile & 1 & 2 & 3 & 4 & 5 & 1 & 2 & 3 & 4 & 5 \\
\hline Jensen's $\alpha$ & -0.33 & -1.23 & -1.91 & -1.96 & -1.46 & -0.57 & -0.91 & -0.80 & -1.63 & -1.65 \\
\hline Market $\beta$ & 1.02 & $1.18^{c}$ & $1.29^{b}$ & $1.28^{c}$ & 1.36 & 0.98 & 1.01 & 1.09 & $1.17^{c}$ & $1.22^{c}$ \\
\hline $\mathrm{R}^{2}$ & 0.97 & 0.81 & 0.77 & 0.62 & 0.50 & 0.92 & 0.87 & 0.82 & 0.79 & 0.71 \\
\hline & \multicolumn{5}{|c|}{ Panel E: Averaging method } & \multicolumn{5}{|c|}{ Panel F: Autoregressive method } \\
\hline Quintile & 1 & 2 & 3 & 4 & 5 & 1 & 2 & 3 & 4 & 5 \\
\hline Jensen's $\alpha$ & -0.06 & -0.33 & -0.69 & -1.13 & -1.26 & -1.46 & -1.37 & -1.05 & -1.62 & -1.74 \\
\hline Market $\beta$ & 0.93 & 0.97 & 1.01 & $1.20^{b}$ & 1.12 & 1.12 & 1.08 & 1.14 & 1.19 & $1.23^{c}$ \\
\hline \multirow[t]{2}{*}{$\mathrm{R}^{2}$} & 0.84 & 0.84 & 0.79 & 0.79 & 0.71 & 0.49 & 0.68 & 0.65 & 0.73 & 0.72 \\
\hline & \multicolumn{5}{|c|}{ Panel G: Random walk method } & \multicolumn{5}{|c|}{ Panel H: Business cycle method } \\
\hline Quintile & 1 & 2 & 3 & 4 & 5 & 1 & 2 & 3 & 4 & 5 \\
\hline Jensen's $\alpha$ & -1.07 & -1.41 & -1.57 & -1.83 & -1.80 & $1.49^{c}$ & -0.15 & -0.86 & -1.44 & -1.86 \\
\hline Market $\beta$ & 1.14 & $1.14^{c}$ & $1.17^{c}$ & $1.24^{b}$ & $1.22^{c}$ & 0.83 & 0.96 & 1.13 & 1.20 & $1.26^{c}$ \\
\hline $\mathrm{R}^{2}$ & 0.77 & 0.85 & 0.80 & 0.76 & 0.74 & 0.50 & 0.64 & 0.74 & 0.73 & 0.72 \\
\hline
\end{tabular}

Note: This table shows the results from the regression of quarterly portfolio returns on a constant and returns on an equally-weighted market index. Estimates for the constant and slope parameters are denoted by Jensen's $\alpha$ and market $\beta$, respectively. The portfolio returns result from applying several forecasting methods. Panels A through $\mathrm{H}$ relate each to a particular method. The Portfolios $q, q=1, \ldots, 5$, are obtained after ranking the positive return forecasts from a particular method and dividing up into quintiles. Portfolio 1 is based on stocks with the strongest ex-ante predicted outperformance. Significance is denoted by superscripts at the $1 \%\left({ }^{a}\right), 5 \%\left({ }^{b}\right)$, and $10 \%\left({ }^{c}\right)$ level, where we use a one-sided test for $\alpha>0$ and a two-sided test for $\beta \neq 1$. The symbol $R^{2}$ denotes the coefficient of determination. 
Table 8: Semi-Annual Risk Analysis: Market Risk Model

\begin{tabular}{|c|c|c|c|c|c|c|c|c|c|c|}
\hline \multirow[b]{2}{*}{ Quintile } & \multicolumn{5}{|c|}{ Panel A: Perfect foresight } & \multicolumn{5}{|c|}{ Panel B: Fixed BM method } \\
\hline & 1 & 2 & 3 & 4 & 5 & 1 & 2 & 3 & 4 & 5 \\
\hline Jensen's $\alpha$ & $9.59^{b}$ & 2.98 & 1.15 & -1.03 & -1.65 & -0.77 & -1.47 & -2.16 & -2.47 & -3.85 \\
\hline Market $\beta$ & 1.10 & 0.93 & 0.94 & 1.06 & 1.02 & 1.12 & 1.02 & 1.05 & 1.08 & $1.45^{c}$ \\
\hline \multirow[t]{2}{*}{$\mathrm{R}^{2}$} & 0.23 & 0.46 & 0.54 & 0.53 & 0.52 & 0.29 & 0.51 & 0.62 & 0.63 & 0.64 \\
\hline & \multicolumn{5}{|c|}{ Panel C: Fixed Size method } & \multicolumn{5}{|c|}{ Panel D: Pooling method } \\
\hline Quint & 1 & 2 & 3 & 4 & 5 & 1 & 2 & 3 & 4 & 5 \\
\hline Jen & -0.51 & -1.70 & -3.25 & -4.86 & -0.39 & 3.51 & -3.46 & -2.28 & -2.36 & -1.53 \\
\hline Mar & 0.97 & 1.01 & 1.10 & 1.29 & 1.36 & 1.33 & 1.23 & 1.11 & 0.99 & 1.02 \\
\hline $\mathrm{R}^{2}$ & 0.94 & 0.65 & 0.55 & 0.59 & 0.32 & 0.49 & 0.61 & 0.56 & 0.49 & 0.49 \\
\hline & \multicolumn{5}{|c|}{ Panel E: Averaging method } & \multicolumn{5}{|c|}{ Panel F: Autoregressive method } \\
\hline Quir & 1 & 2 & 3 & 4 & 5 & 1 & 2 & 3 & 4 & 5 \\
\hline Jen & 2.03 & 0.22 & -1.47 & -2.96 & -2.62 & 2.08 & 0.18 & -0.02 & -1.30 & -2.35 \\
\hline Market $\beta$ & 0.75 & 0.90 & 1.02 & 1.25 & 1.11 & 1.32 & 1.13 & 0.94 & 1.07 & 1.07 \\
\hline \multirow[t]{2}{*}{$\mathrm{R}^{2}$} & 0.16 & 0.43 & 0.50 & 0.65 & 0.57 & 0.39 & 0.48 & 0.50 & 0.53 & 0.57 \\
\hline & \multicolumn{5}{|c|}{ Panel G: Random walk method } & \multicolumn{5}{|c|}{ Panel H: Business cycle method } \\
\hline Quintile & 1 & 2 & 3 & 4 & 5 & 1 & 2 & 3 & 4 & 5 \\
\hline Jense & -3.99 & -3.53 & -3.75 & -3.55 & -3.37 & $5.42^{b}$ & 0.67 & -2.28 & -2.91 & -3.73 \\
\hline Mark & 1.32 & 1.26 & 1.25 & 1.11 & 1.11 & 0.67 & 0.97 & 1.12 & 1.05 & 1.07 \\
\hline $\mathrm{R}^{2}$ & 0.62 & 0.73 & 0.71 & 0.61 & 0.56 & 0.22 & 0.56 & 0.73 & 0.62 & 0.55 \\
\hline
\end{tabular}

Note: This table shows the results from the regression of semi-annual portfolio returns on a constant and returns on an equally-weighted market index. Estimates for the constant and slope parameters are denoted by Jensen's $\alpha$ and market $\beta$, respectively. The portfolio returns result from applying several forecasting methods. Panels A through $\mathrm{H}$ relate each to a particular method. The Portfolios $q, q=1, \ldots, 5$, are obtained after ranking the positive return forecasts from a particular method and dividing up into quintiles. Portfolio 1 is based on stocks with the strongest ex-ante predicted outperformance. Significance is denoted by superscripts at the $1 \%\left({ }^{a}\right), 5 \%\left({ }^{b}\right)$, and $10 \%\left({ }^{c}\right)$ level, where we use a one-sided test for $\alpha>0$ and a two-sided test for $\beta \neq 1$. The symbol $R^{2}$ denotes the coefficient of determination. 
Table 9: Annual Risk Analysis: Market Risk Model

\begin{tabular}{lccccccccccr}
\hline \hline & \multicolumn{4}{c}{ Panel A: Perfect foresight } & \multicolumn{4}{c}{ Panel B: Fixed BM method } \\
Quintile & 1 & 2 & 3 & 4 & 5 & 1 & 2 & 3 & 4 & 5 \\
Jensen's $\alpha$ & $22.9^{a}$ & $10.1^{c}$ & -2.44 & 0.15 & -3.59 & 3.58 & 0.12 & 2.27 & 2.34 & 1.74 \\
Market $\beta$ & 0.63 & 0.75 & 1.12 & 0.75 & 0.96 & 0.72 & 0.80 & 0.70 & 0.73 & 0.94 \\
$\mathrm{R}^{2}$ & 0.20 & 0.34 & 0.64 & 0.48 & 0.53 & 0.25 & 0.43 & 0.42 & 0.71 & 0.44
\end{tabular}

Panel C: Fixed Size method

$\begin{array}{llrrrrrrrrr}\text { Quintile } & 1 & 2 & 3 & 4 & 5 & 1 & 2 & 3 & 4 & 5 \\ \text { Jensen's } \alpha & 0.65 & -0.43 & -1.02 & -3.74 & 14.5^{b} & 7.02 & 4.28 & 0.12 & -2.03 & -1.84 \\ \text { Market } \beta & 0.84^{c} & 0.73 & 0.63 & 0.91 & 0.77 & 1.04 & 0.81 & 0.94 & 0.84 & 0.79 \\ \mathrm{R}^{2} & 0.93 & 0.54 & 0.49 & 0.52 & 0.27 & 0.48 & 0.35 & 0.43 & 0.59 & 0.40\end{array}$

\begin{tabular}{lrrrrrrrrrr} 
& \multicolumn{4}{c}{ Panel E: Averaging method } & \multicolumn{4}{c}{ Panel F: Autoregressive method } \\
Quintile & 1 & 2 & 3 & 4 & 5 & 1 & 2 & 3 & 4 & 5 \\
Jensen's $\alpha$ & 7.14 & 3.45 & 2.32 & -0.73 & 1.18 & 1.01 & 0.09 & -0.16 & -1.87 & 0.27 \\
Market $\beta$ & 0.82 & 0.88 & 0.67 & 0.89 & 0.86 & 1.28 & 0.96 & 0.86 & 0.78 & $0.58^{c}$ \\
$\mathrm{R}^{2}$ & 0.26 & 0.45 & 0.28 & 0.43 & 0.38 & 0.37 & 0.46 & 0.49 & 0.58 & 0.53
\end{tabular}

$\begin{array}{llrrrrrrrrr}\text { Quintile } & 1 & 2 & 3 & 4 & 5 & 1 & 2 & 3 & 4 & 5 \\ \text { Jensen's } \alpha & 17.2^{b} & 7.04 & 2.12 & -2.35 & -1.38 & 12.6^{c} & 3.93 & 2.06 & -0.51 & -2.54 \\ \text { Market } \beta & 0.76 & 0.82 & 0.72 & 0.83 & 0.68 & 0.73 & 0.86 & 0.73 & 0.79 & 0.82 \\ \mathrm{R}^{2} & 0.19 & 0.31 & 0.39 & 0.51 & 0.44 & 0.19 & 0.46 & 0.51 & 0.52 & 0.51\end{array}$

Note: This table shows the results from the regression of annual portfolio returns on a constant and returns on an equally-weighted market index. Estimates for the constant and slope parameters are denoted by Jensen's $\alpha$ and market $\beta$, respectively. The portfolio returns result from applying several forecasting methods. Panels A through $\mathrm{H}$ relate each to a particular method. The Portfolios $q, q=1, \ldots, 5$, are obtained after ranking the positive return forecasts from a particular method and dividing up into quintiles. Portfolio 1 is based on stocks with the strongest ex-ante predicted outperformance. Significance is denoted by superscripts at the $1 \%\left({ }^{a}\right), 5 \%\left({ }^{b}\right)$, and $10 \%\left({ }^{c}\right)$ level, where we use a one-sided test for $\alpha>0$ and a two-sided test for $\beta \neq 1$. The symbol $R^{2}$ denotes the coefficient of determination. 
Table 10: Monthly Risk Analysis: the FF Risk Model

\begin{tabular}{|c|c|c|c|c|c|c|c|c|c|c|}
\hline \multirow[b]{2}{*}{ Quintile } & \multicolumn{5}{|c|}{ Panel A: Perfect foresight } & \multicolumn{5}{|c|}{ Panel B: Fixed BM method } \\
\hline & 1 & 2 & 3 & 4 & 5 & 1 & 2 & 3 & 4 & 5 \\
\hline$F F_{\alpha}$ & $2.09^{a}$ & $1.33^{a}$ & $1.00^{a}$ & $0.52^{a}$ & $0.19^{c}$ & $0.19^{b}$ & 0.06 & -0.18 & -0.15 & 0.04 \\
\hline$F F_{R m}$ & 1.06 & 1.04 & 1.02 & $1.08^{a}$ & 1.05 & $0.94^{b}$ & $0.90^{a}$ & 0.98 & $1.10^{c}$ & $1.28^{a}$ \\
\hline$F F_{H M L}$ & $0.26^{a}$ & $0.21^{a}$ & $0.19^{a}$ & $0.15^{a}$ & $0.11^{b}$ & $0.66^{a}$ & $0.40^{a}$ & $0.20^{a}$ & -0.05 & $-0.47^{a}$ \\
\hline$F F_{S M B}$ & $0.76^{a}$ & $0.68^{a}$ & $0.73^{a}$ & $0.71^{a}$ & $0.72^{a}$ & $0.95^{a}$ & $0.59^{a}$ & $0.63^{a}$ & $0.68^{a}$ & $0.85^{a}$ \\
\hline \multirow[t]{2}{*}{$\mathrm{R}^{2}$} & 0.84 & 0.93 & 0.94 & 0.95 & 0.94 & 0.97 & 0.97 & 0.97 & 0.97 & 0.97 \\
\hline & \multicolumn{5}{|c|}{ Panel C: Fixed Size method } & \multicolumn{5}{|c|}{ Panel D: Pooling method } \\
\hline Quintile & 1 & 2 & 3 & 4 & 5 & 1 & 2 & 3 & 4 & 5 \\
\hline$F F_{\alpha}$ & -0.09 & -0.07 & 0.01 & 0.03 & 0.08 & -0.07 & -0.11 & -0.08 & -0.03 & -0.01 \\
\hline$F F_{R m}$ & 1.01 & $1.06^{b}$ & $1.07^{a}$ & $1.05^{a}$ & 1.00 & 0.98 & 1.01 & 1.03 & 1.04 & 1.01 \\
\hline$F F_{H M L}$ & $0.15^{a}$ & $0.15^{a}$ & 0.04 & $0.09^{a}$ & $0.31^{a}$ & $0.18^{a}$ & $0.27^{a}$ & $0.29^{a}$ & $0.22^{a}$ & $0.17^{a}$ \\
\hline$F F_{S M B}$ & $0.09^{a}$ & $0.53^{a}$ & $0.82^{a}$ & $0.99^{a}$ & $1.26^{a}$ & -0.01 & $0.19^{a}$ & $0.36^{a}$ & $0.57^{a}$ & $0.69^{a}$ \\
\hline \multirow[t]{2}{*}{$\mathrm{R}^{2}$} & 0.98 & 0.95 & 0.97 & 0.99 & 0.93 & 0.98 & 0.96 & 0.94 & 0.95 & 0.93 \\
\hline & \multicolumn{5}{|c|}{ Panel E: Averaging method } & \multicolumn{5}{|c|}{ Panel F: Autoregressive method } \\
\hline Quintile & 1 & 2 & 3 & 4 & 5 & 1 & 2 & 3 & 4 & 5 \\
\hline$F F_{\alpha}$ & -0.06 & -0.09 & -0.13 & 0.00 & -0.01 & 0.09 & 0.04 & 0.08 & -0.06 & -0.03 \\
\hline$F F_{R m}$ & $0.98^{c}$ & 1.02 & 1.03 & 1.04 & 1.01 & 0.98 & 1.00 & 1.00 & $1.06^{b}$ & 1.03 \\
\hline$F F_{H M L}$ & $0.18^{a}$ & $0.27^{a}$ & $0.30^{a}$ & $0.21^{a}$ & $0.19^{a}$ & $0.23^{a}$ & $0.22^{a}$ & $0.17^{a}$ & $0.21^{a}$ & $0.13^{a}$ \\
\hline$F F_{S M B}$ & -0.00 & $0.20^{a}$ & $0.37^{a}$ & $0.56^{a}$ & $0.70^{a}$ & $0.15^{a}$ & $0.33^{a}$ & $0.46^{a}$ & $0.58^{a}$ & $0.72^{a}$ \\
\hline $\mathrm{R}^{2}$ & 0.98 & 0.95 & 0.94 & 0.95 & 0.93 & 0.89 & 0.93 & 0.93 & 0.95 & 0.94 \\
\hline
\end{tabular}

Panel G: Random walk method

\begin{tabular}{|c|c|c|c|c|c|c|c|c|c|c|}
\hline Quintile & 1 & 2 & 3 & 4 & 5 & 1 & 2 & 3 & 4 & 5 \\
\hline$F F_{\alpha}$ & 0.24 & $0.21^{c}$ & 0.16 & -0.02 & -0.04 & $0.41^{b}$ & 0.19 & 0.06 & 0.00 & 0.02 \\
\hline$F F_{R m}$ & 0.95 & 0.96 & 1.00 & 1.03 & $1.08^{a}$ & 0.97 & 1.00 & 1.04 & $1.05^{c}$ & 1.04 \\
\hline$F F_{H M}$ & 0.11 & $0.16^{a}$ & $0.17^{a}$ & $0.12^{b}$ & $0.15^{a}$ & $0.18^{b}$ & $0.19^{a}$ & $0.16^{a}$ & $0.14^{a}$ & $0.12^{a}$ \\
\hline$F F_{S M B}$ & $0.45^{a}$ & $0.55^{a}$ & $0.64^{a}$ & $0.65^{a}$ & $0.71^{a}$ & $0.31^{a}$ & $0.39^{a}$ & $0.52^{a}$ & $0.62^{a}$ & $0.73^{a}$ \\
\hline $\mathrm{R}^{2}$ & 0.73 & 0.86 & 0.91 & 0.93 & 0.95 & 0.78 & 0.87 & 0.92 & 0.93 & 0.94 \\
\hline
\end{tabular}

Note: This table shows the results from the regression of monthly portfolio returns on a constant $\left(F F_{\alpha}\right)$ and the Fama and French risk factors. These factors are a market return factor $\left(F F_{R m}\right)$, a return differential of high $\mathrm{B} / \mathrm{P}$ minus low $\mathrm{B} / \mathrm{P}$ firms $\left(F F_{H M L}\right)$, and a return differential of small minus big firms $\left(F F_{S M B}\right)$. The latter two are orthogonalized with respect to $\left(F F_{R m}\right)$. The portfolio returns result from applying several forecasting methods. Panels A through $\mathrm{H}$ relate each to a particular method. The Portfolios $q, q=1, \ldots, 5$, are obtained after ranking the positive return forecasts from a particular method and dividing up into quintiles. Portfolio 1 is based on stocks with the strongest ex-ante predicted outperformance. Significance is denoted by superscripts at the $1 \%\left({ }^{a}\right), 5 \%\left({ }^{b}\right)$, and $10 \%\left({ }^{c}\right)$ level, where we use a one-sided test for $F F_{\alpha}>0$, a two-sided test for $F F_{R m} \neq 1$, and two-sided tests for $F F_{H M L} \neq 0$ and $F F_{S M B} \neq 0$. The symbol $R^{2}$ denotes the coefficient of determination. 
Table 11: Quarterly Risk Analysis: the FF Risk Model

\begin{tabular}{|c|c|c|c|c|c|c|c|c|c|c|}
\hline \multirow[b]{2}{*}{ Quintile } & \multicolumn{5}{|c|}{ Panel A: Perfect foresight } & \multicolumn{5}{|c|}{ Panel B: Fixed BM method } \\
\hline & 1 & 2 & 3 & 4 & 5 & 1 & 2 & 3 & 4 & 5 \\
\hline$F F_{\alpha}$ & $5.58^{a}$ & $2.99^{a}$ & $2.19^{a}$ & $0.66^{b}$ & -0.52 & $0.96^{a}$ & 0.16 & -0.35 & -0.39 & -0.04 \\
\hline$F F_{R m}$ & 1.17 & $1.13^{c}$ & $1.12^{c}$ & $1.26^{a}$ & $1.18^{a}$ & 1.05 & 1.00 & 1.05 & $1.18^{a}$ & $1.42^{a}$ \\
\hline$F F_{H M L}$ & $0.27^{b}$ & 0.13 & $0.20^{b}$ & $0.15^{a}$ & 0.10 & $0.63^{a}$ & $0.35^{a}$ & $0.18^{a}$ & $-0.11^{b}$ & $-0.55^{a}$ \\
\hline$F F_{S M B}$ & $0.98^{a}$ & $0.78^{a}$ & $0.69^{a}$ & $0.69^{a}$ & $0.63^{a}$ & $1.05^{a}$ & $0.61^{a}$ & $0.59^{a}$ & $0.71^{a}$ & $0.78^{a}$ \\
\hline \multirow[t]{2}{*}{$\mathrm{R}^{2}$} & 0.87 & 0.92 & 0.93 & 0.97 & 0.96 & 0.97 & 0.98 & 0.97 & 0.97 & 0.97 \\
\hline & \multicolumn{5}{|c|}{ Panel C: Fixed Size method } & \multicolumn{5}{|c|}{ Panel D: Pooling method } \\
\hline Quintile & 1 & 2 & 3 & 4 & 5 & 1 & 2 & 3 & 4 & 5 \\
\hline$F F_{\alpha}$ & -0.24 & -0.20 & -0.45 & 0.16 & $1.09^{b}$ & -0.33 & -0.35 & 0.13 & -0.59 & -0.27 \\
\hline$F F_{R m}$ & 1.01 & $1.12^{a}$ & $1.20^{a}$ & $1.16^{a}$ & $1.21^{a}$ & 0.96 & 0.98 & 1.03 & $1.11^{a}$ & $1.14^{a}$ \\
\hline$F F_{H M L}$ & $0.10^{a}$ & 0.08 & 0.03 & $0.06^{c}$ & $0.24^{a}$ & -0.04 & 0.06 & 0.06 & $0.14^{a}$ & $0.14^{b}$ \\
\hline$F F_{S M B}$ & $0.09^{a}$ & $0.54^{a}$ & $0.72^{a}$ & $1.05^{a}$ & $1.34^{a}$ & $0.10^{c}$ & $0.30^{a}$ & $0.48^{a}$ & $0.57^{a}$ & $0.73^{a}$ \\
\hline \multirow[t]{2}{*}{$\mathrm{R}^{2}$} & 0.99 & 0.96 & 0.98 & 0.99 & 0.96 & 0.92 & 0.95 & 0.96 & 0.98 & 0.96 \\
\hline & \multicolumn{5}{|c|}{ Panel E: Averaging method } & \multicolumn{5}{|c|}{ Panel F: Autoregressive method } \\
\hline Quintile & 1 & 2 & 3 & 4 & 5 & 1 & 2 & 3 & 4 & 5 \\
\hline$F F_{\alpha}$ & -0.16 & -0.11 & -0.04 & -0.31 & -0.17 & -0.35 & -0.41 & 0.13 & -0.41 & -0.40 \\
\hline$F F_{R m}$ & 0.94 & 0.95 & 0.97 & $1.15^{a}$ & 1.06 & 1.06 & 1.02 & 1.07 & $1.12^{a}$ & $1.15^{a}$ \\
\hline$F F_{H M L}$ & $0.27^{a}$ & $0.28^{a}$ & $0.21^{a}$ & $0.26^{a}$ & $0.25^{a}$ & $0.38^{b}$ & $0.24^{a}$ & $0.31^{a}$ & $0.18^{a}$ & $0.18^{a}$ \\
\hline$F F_{S M B}$ & 0.07 & $0.23^{a}$ & $0.41^{a}$ & $0.51^{a}$ & $0.64^{a}$ & $0.71^{a}$ & $0.57^{a}$ & $0.71^{a}$ & $0.67^{a}$ & $0.73^{a}$ \\
\hline $\mathrm{R}^{2}$ & 0.90 & 0.95 & 0.95 & 0.97 & 0.97 & 0.74 & 0.90 & 0.94 & 0.97 & 0.98 \\
\hline
\end{tabular}

Panel G: Random walk method

\begin{tabular}{lrrrrrcrrrr} 
Quintile & 1 & 2 & 3 & 4 & 5 & 1 & 2 & 3 & 4 & 5 \\
$F F_{\alpha}$ & -0.83 & -0.65 & -0.39 & -0.44 & -0.32 & $2.06^{b}$ & $0.87^{c}$ & 0.27 & 0.03 & -0.27 \\
$F F_{R m}$ & 1.13 & 1.09 & $1.11^{b}$ & $1.16^{a}$ & $1.13^{b}$ & $0.80^{c}$ & 0.90 & 1.06 & $1.11^{b}$ & $1.16^{a}$ \\
$F F_{H M L}$ & 0.07 & -0.02 & -0.04 & 0.04 & -0.03 & $0.29^{b}$ & 0.09 & 0.06 & -0.01 & -0.01 \\
$F F_{S M B}$ & 0.15 & $0.36^{a}$ & $0.55^{a}$ & $0.69^{a}$ & $0.70^{a}$ & $0.41^{a}$ & $0.54^{a}$ & $0.58^{a}$ & $0.71^{a}$ & $0.77^{a}$ \\
$\mathrm{R}^{2}$ & 0.79 & 0.92 & 0.95 & 0.96 & 0.95 & 0.68 & 0.83 & 0.91 & 0.95 & 0.95 \\
\hline
\end{tabular}

Note: This table shows the results from the regression of quarterly portfolio returns on a constant $\left(F F_{\alpha}\right)$ and the Fama and French risk factors. These factors are a market return factor $\left(F F_{R m}\right)$, a return differential of high $\mathrm{B} / \mathrm{P}$ minus low $\mathrm{B} / \mathrm{P}$ firms $\left(F F_{H M L}\right)$, and a return differential of small minus big firms $\left(F F_{S M B}\right)$. The latter two are orthogonalized with respect to $\left(F F_{R m}\right)$. The portfolio returns result from applying several forecasting methods. Panels A through $\mathrm{H}$ relate each to a particular method. The Portfolios $q, q=1, \ldots, 5$, are obtained after ranking the positive return forecasts from a particular method and dividing up into quintiles. Portfolio 1 is based on stocks with the strongest ex-ante predicted outperformance. Significance is denoted by superscripts at the $1 \%\left({ }^{a}\right), 5 \%\left({ }^{b}\right)$, and $10 \%\left({ }^{c}\right)$ level, where we use a one-sided test for $F F_{\alpha}>0$, a two-sided test for $F F_{R m} \neq 1$, and two-sided tests for $F F_{H M L} \neq 0$ and $F F_{S M B} \neq 0$. The symbol $R^{2}$ denotes the coefficient of determination. 
Table 12: Semi-Annual Risk Analysis: the FF Risk Model

\begin{tabular}{|c|c|c|c|c|c|c|c|c|c|c|}
\hline \multirow[b]{2}{*}{ Quintile } & \multicolumn{5}{|c|}{$\overline{\text { Panel A: Perfect foresight }}$} & \multicolumn{5}{|c|}{ Panel B: Fixed BM method } \\
\hline & 1 & 2 & 3 & 4 & 5 & 1 & 2 & 3 & 4 & 5 \\
\hline$F F_{\alpha}$ & $13.3^{a}$ & $5.77^{a}$ & $3.68^{a}$ & 1.39 & 1.13 & $2.12^{a}$ & 0.17 & 0.16 & 0.68 & 0.56 \\
\hline$F F_{R m}$ & 0.84 & $0.73^{c}$ & $0.76^{b}$ & 0.89 & 0.82 & 0.92 & 0.90 & 0.89 & $0.86^{b}$ & 1.13 \\
\hline$F F_{H M L}$ & 0.36 & 0.05 & 0.05 & $0.18^{b}$ & 0.06 & $0.68^{a}$ & $0.38^{a}$ & $0.11^{c}$ & $-0.11^{b}$ & $-0.55^{a}$ \\
\hline$F F_{S M B}$ & $1.12^{a}$ & $0.74^{a}$ & $0.67^{a}$ & $0.70^{a}$ & $0.74^{a}$ & $1.06^{a}$ & $0.60^{a}$ & $0.64^{a}$ & $0.75^{a}$ & $0.87^{a}$ \\
\hline \multirow[t]{2}{*}{$\mathrm{R}^{2}$} & 0.65 & 0.84 & 0.91 & 0.92 & 0.88 & 0.98 & 0.97 & 0.96 & 0.98 & 0.93 \\
\hline & \multicolumn{5}{|c|}{ Panel C: Fixed Size method } & \multicolumn{5}{|c|}{ Panel D: Pooling method } \\
\hline Quintile & 1 & 2 & 3 & 4 & 5 & 1 & 2 & 3 & 4 & 5 \\
\hline$F F_{\alpha}$ & -0.12 & 0.45 & 0.01 & -0.95 & $4.34^{b}$ & -0.40 & -0.10 & 0.53 & $0.87^{c}$ & $1.29^{c}$ \\
\hline$F F_{R m}$ & 0.94 & 0.86 & $0.87^{c}$ & 1.01 & 1.02 & 1.11 & 0.99 & 0.92 & $0.76^{a}$ & $0.82^{c}$ \\
\hline$F F_{H M L}$ & $0.06^{c}$ & 0.06 & 0.03 & -0.06 & $0.41^{b}$ & -0.29 & $-0.30^{b}$ & 0.07 & 0.06 & $0.14^{c}$ \\
\hline$F F_{S M B}$ & $0.13^{a}$ & $0.58^{a}$ & $0.85^{a}$ & $0.97^{a}$ & $1.40^{a}$ & $0.65^{b}$ & $0.72^{a}$ & $0.75^{a}$ & $0.85^{a}$ & $0.79^{a}$ \\
\hline \multirow[t]{2}{*}{$\mathrm{R}^{2}$} & 0.97 & 0.93 & 0.97 & 0.98 & 0.90 & 0.62 & 0.84 & 0.91 & 0.97 & 0.94 \\
\hline & \multicolumn{5}{|c|}{ Panel E: Averaging method } & \multicolumn{5}{|c|}{ Panel F: Autoregressive method } \\
\hline Quintile & 1 & 2 & 3 & 4 & 5 & 1 & 2 & 3 & 4 & 5 \\
\hline$F F_{\alpha}$ & 2.12 & 1.34 & 0.99 & -0.34 & 0.56 & $4.66^{c}$ & $3.08^{b}$ & $1.92^{c}$ & $1.53^{c}$ & 0.58 \\
\hline$F F_{R m}$ & 0.74 & 0.82 & 0.84 & 1.06 & 0.88 & 1.13 & 0.93 & 0.80 & 0.87 & 0.86 \\
\hline$F F_{H M L}$ & $0.85^{a}$ & $0.43^{a}$ & $0.19^{b}$ & 0.06 & 0.01 & 0.38 & 0.19 & $0.20^{c}$ & 0.12 & 0.03 \\
\hline$F F_{S M B}$ & 0.42 & $0.49^{a}$ & $0.72^{a}$ & $0.70^{a}$ & $0.82^{a}$ & $0.84^{a}$ & $0.83^{a}$ & $0.59^{a}$ & $0.78^{a}$ & $0.76^{a}$ \\
\hline & 0.69 & 0.87 & 0.91 & 0.93 & 0.96 & 0.72 & 0.89 & 0.86 & 0.94 & 0.95 \\
\hline
\end{tabular}

Panel G: Random walk method

\begin{tabular}{lrrrrrrrrrr} 
Quintile & 1 & 2 & 3 & 4 & 5 & 1 & 2 & 3 & 4 & 5 \\
$F F_{\alpha}$ & -2.82 & -1.59 & -0.86 & -0.80 & -0.30 & $6.36^{a}$ & $2.73^{b}$ & -0.34 & -0.62 & -0.74 \\
$F F_{R m}$ & 1.24 & 1.12 & 1.05 & 0.92 & 0.89 & $0.61^{c}$ & 0.82 & 0.98 & 0.89 & 0.86 \\
$F F_{H M L}$ & 0.14 & 0.01 & -0.11 & 0.05 & 0.04 & $0.50^{a}$ & 0.08 & 0.06 & 0.06 & 0.01 \\
$F F_{S M B}$ & 0.36 & $0.50^{a}$ & $0.69^{a}$ & $0.73^{a}$ & $0.80^{a}$ & $0.48^{b}$ & $0.56^{a}$ & $0.52^{a}$ & $0.61^{a}$ & $0.77^{a}$ \\
$\mathrm{R}^{2}$ & 0.71 & 0.88 & 0.95 & 0.96 & 0.94 & 0.70 & 0.83 & 0.95 & 0.90 & 0.91 \\
\hline
\end{tabular}

Note: This table shows the results from the regression of semi-annual portfolio returns on a constant $\left(F F_{\alpha}\right)$ and the Fama and French risk factors. These factors are a market return factor $\left(F F_{R m}\right)$, a return differential of high $\mathrm{B} / \mathrm{P}$ minus low $\mathrm{B} / \mathrm{P}$ firms $\left(F F_{H M L}\right)$, and a return differential of small minus big firms $\left(F F_{S M B}\right)$. The latter two are orthogonalized with respect to $\left(F F_{R m}\right)$. The portfolio returns result from applying several forecasting methods. Panels A through $\mathrm{H}$ relate each to a particular method. The Portfolios $q, q=1, \ldots, 5$, are obtained after ranking the positive return forecasts from a particular method and dividing up into quintiles. Portfolio 1 is based on stocks with the strongest ex-ante predicted outperformance. Significance is denoted by superscripts at the $1 \%\left({ }^{a}\right), 5 \%\left({ }^{b}\right)$, and $10 \%\left({ }^{c}\right)$ level, where we use a one-sided test for $F F_{\alpha}>0$, a two-sided test for $F F_{R m} \neq 1$, and two-sided tests for $F F_{H M L} \neq 0$ and $F F_{S M B} \neq 0$. The symbol $R^{2}$ denotes the coefficient of determination. 
Table 13: Annual Risk Analysis: the FF Risk Model

\begin{tabular}{|c|c|c|c|c|c|c|c|c|c|c|}
\hline \multirow[b]{2}{*}{ Quintile } & \multicolumn{5}{|c|}{ Panel A: Perfect foresight } & \multicolumn{5}{|c|}{ Panel B: Fixed BM method } \\
\hline & 1 & 2 & 3 & 4 & 5 & 1 & 2 & 3 & 4 & 5 \\
\hline$F F_{\alpha}$ & $23.2^{a}$ & $10.5^{a}$ & -2.06 & 0.53 & -3.16 & $4.30^{b}$ & 0.63 & $2.63^{b}$ & $2.41^{b}$ & 1.43 \\
\hline$F F_{R m}$ & 0.61 & 0.73 & 1.10 & 0.73 & 0.93 & $0.69^{b}$ & 0.77 & $0.68^{a}$ & $0.72^{a}$ & 0.95 \\
\hline$F F_{H M L}$ & -0.10 & 0.11 & 0.30 & $0.31^{c}$ & $0.28^{b}$ & $0.65^{a}$ & $0.50^{a}$ & $0.19^{b}$ & $-0.11^{c}$ & $-0.74^{a}$ \\
\hline$F F_{S M B}$ & $1.46^{b}$ & $1.09^{b}$ & 0.55 & $0.52^{c}$ & $0.80^{a}$ & $0.78^{a}$ & $0.43^{c}$ & $0.84^{a}$ & $0.64^{a}$ & $1.14^{a}$ \\
\hline \multirow[t]{2}{*}{$\mathrm{R}^{2}$} & 0.77 & 0.85 & 0.88 & 0.88 & 0.94 & 0.96 & 0.92 & 0.97 & 0.97 & 0.88 \\
\hline & \multicolumn{5}{|c|}{ Panel C: Fixed Size method } & \multicolumn{5}{|c|}{ Panel D: Pooling method } \\
\hline Quintile & 1 & 2 & 3 & 4 & 5 & 1 & 2 & 3 & 4 & 5 \\
\hline$F F_{\alpha}$ & 0.73 & -0.16 & -0.81 & -3.35 & $14.9^{a}$ & $7.41^{c}$ & $4.61^{b}$ & 0.43 & -1.74 & -1.47 \\
\hline$F F_{R m}$ & $0.83^{b}$ & $0.72^{b}$ & $0.62^{b}$ & 0.89 & 0.75 & 1.02 & 0.79 & 0.92 & 0.83 & $0.77^{b}$ \\
\hline$F F_{H M L}$ & 0.05 & 0.12 & 0.05 & $0.21^{b}$ & 0.08 & 0.20 & -0.02 & -0.01 & 0.16 & 0.10 \\
\hline$F F_{S M B}$ & 0.17 & $0.70^{a}$ & $0.69^{a}$ & $0.91^{a}$ & $1.34^{b}$ & $0.92^{c}$ & $1.37^{a}$ & $1.28^{a}$ & $0.65^{b}$ & $1.14^{a}$ \\
\hline \multirow[t]{2}{*}{$\mathrm{R}^{2}$} & 0.97 & 0.93 & 0.90 & 0.98 & 0.79 & 0.80 & 0.94 & 0.90 & 0.92 & 0.97 \\
\hline & \multicolumn{5}{|c|}{ Panel E: Averaging method } & \multicolumn{5}{|c|}{ Panel F: Autoregressive method } \\
\hline Quintile & 1 & 2 & 3 & 4 & 5 & 1 & 2 & 3 & 4 & 5 \\
\hline$F F_{\alpha}$ & $7.79^{c}$ & $3.98^{c}$ & $2.86^{c}$ & -0.42 & 1.48 & 1.15 & 0.35 & 0.17 & -1.66 & 0.50 \\
\hline$F F_{R m}$ & 0.79 & 0.86 & $0.64^{b}$ & 0.87 & 0.84 & 1.27 & 0.94 & 0.84 & 0.77 & $0.57^{b}$ \\
\hline$F F_{H M L}$ & 0.48 & $0.45^{b}$ & $0.37^{a}$ & 0.01 & -0.03 & -0.34 & -0.01 & 0.17 & 0.04 & 0.14 \\
\hline$F F_{S M B}$ & $1.02^{c}$ & $0.63^{b}$ & $0.96^{a}$ & $1.22^{a}$ & $1.30^{a}$ & $1.67^{c}$ & $1.03^{b}$ & $0.79^{b}$ & $0.71^{b}$ & $0.46^{b}$ \\
\hline $\mathrm{R}^{2}$ & 0.80 & 0.93 & 0.96 & 0.92 & 0.89 & 0.67 & 0.78 & 0.84 & 0.88 & 0.87 \\
\hline
\end{tabular}

Panel G: Random walk method

\begin{tabular}{lcccccccccc} 
Quintile & 1 & 2 & 3 & 4 & 5 & 1 & 2 & 3 & 4 & 5 \\
$F F_{\alpha}$ & $17.4^{a}$ & $7.52^{a}$ & 2.45 & -2.02 & -1.11 & $13.1^{a}$ & 4.13 & 2.28 & -0.16 & -2.22 \\
$F F_{R m}$ & 0.75 & 0.80 & 0.71 & 0.81 & $0.66^{c}$ & 0.70 & 0.85 & $0.72^{c}$ & $0.77^{c}$ & 0.81 \\
$F F_{H M L}$ & -0.31 & 0.17 & 0.13 & 0.16 & 0.09 & 0.06 & -0.08 & 0.03 & $0.21^{c}$ & 0.12 \\
$F F_{S M B}$ & $1.91^{a}$ & $1.37^{a}$ & $0.88^{b}$ & $0.80^{a}$ & $0.78^{b}$ & $1.75^{a}$ & $1.08^{b}$ & $0.78^{a}$ & $0.70^{a}$ & $0.87^{a}$ \\
$\mathrm{R}^{2}$ & 0.78 & 0.94 & 0.84 & 0.91 & 0.87 & 0.88 & 0.84 & 0.89 & 0.94 & 0.93 \\
\hline
\end{tabular}

Note: This table shows the results from the regression of annual portfolio returns on a constant $\left(F F_{\alpha}\right)$ and the Fama and French risk factors. These factors are a market return factor $\left(F F_{R m}\right)$, a return differential of high $\mathrm{B} / \mathrm{P}$ minus low $\mathrm{B} / \mathrm{P}$ firms $\left(F F_{H M L}\right)$, and a return differential of small minus big firms $\left(F F_{S M B}\right)$. The latter two are orthogonalized with respect to $\left(F F_{R m}\right)$. The portfolio returns result from applying several forecasting methods. Panels A through $\mathrm{H}$ relate each to a particular method. The Portfolios $q, q=1, \ldots, 5$, are obtained after ranking the positive return forecasts from a particular method and dividing up into quintiles. Portfolio 1 is based on stocks with the strongest ex-ante predicted outperformance. Significance is denoted by superscripts at the $1 \%\left({ }^{a}\right), 5 \%\left({ }^{b}\right)$, and $10 \%\left({ }^{c}\right)$ level, where we use a one-sided test for $F F_{\alpha}>0$, a two-sided test for $F F_{R m} \neq 1$, and two-sided tests for $F F_{H M L} \neq 0$ and $F F_{S M B} \neq 0$. The symbol $R^{2}$ denotes the coefficient of determination. 